\title{
Trends in work stoppages: A global perspective
}

\author{
Working Paper No. 47
}

\section{J. Perry and Patrick J. Wilson}

Policy Integration Department

Statistical Development and Analysis Unit

International Labour Office

Geneva

November 2004

Working papers are preliminary documents circulated to stimulate discussion and obtain comments 
Copyright (C) International Labour Organization 2004

Publications of the International Labour Office enjoy copyright under Protocol 2 of the Universal Copyright Convention. Nevertheless, short excerpts from them may be reproduced without authorization, on condition that the source is indicated. For rights of reproduction or translation, application should be made to the Publications Bureau (Rights and Permissions), International Labour Office, CH-1211 Geneva 22, Switzerland. The International Labour Office welcomes such applications.

Libraries, institutions and other users registered in the United Kingdom with the Copyright Licensing Agency, 90 Tottenham Court Road, London W1T 4LP [Fax: (+44) (0)20 7631 5500; email: cla@cla.co.uk], in the United States with the Copyright Clearance Center, 222 Rosewood Drive, Danvers, MA 01923 [Fax: (+1) (978) 750 4470; email: info@copyright.com] or in other countries with associated Reproduction Rights Organizations, may make photocopies in accordance with the licences issued to them for this purpose.

ISBN 92-2-116682-1 (printed version)

ISBN 92-2-116683-X (Web version)

First published 2004

Cover:

The designations employed in ILO publications, which are in conformity with United Nations practice, and the presentation of material therein do not imply the expression of any opinion whatsoever on the part of the International Labour Office concerning the legal status of any country, area or territory or of its authorities, or concerning the delimitation of its frontiers.

The responsibility for opinions expressed in signed articles, studies and other contributions rests solely with their authors, and publication does not constitute an endorsement by the International Labour Office of the opinions expressed in them.

Reference to names of firms and commercial products and processes does not imply their endorsement by the International Labour Office, and any failure to mention a particular firm, commercial product or process is not a sign of disapproval.

ILO publications can be obtained through major booksellers or ILO local offices in many countries, or direct from ILO Publications, International Labour Office, $\mathrm{CH}-1211$ Geneva 22, Switzerland. Catalogues or lists of new publications are available free of charge from the above address, or by email: pubvente@ilo.org

Visit our website: www.ilo.org/publns 


\section{Trends in work stoppages: A global perspective}

\section{Contents}

Abstract

Acknowledgments

Preface

1. Measuring International Work Stoppage Statistics.............................................. 1

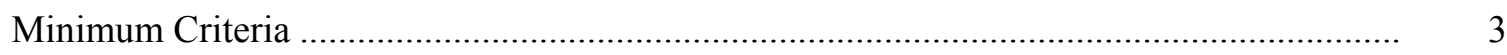

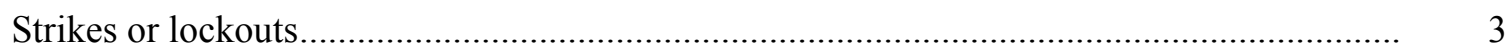

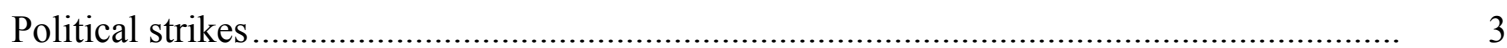

Workers Indirectly Involved in Work Stoppages.......................................................... 3

Minimum Collection Period.....................................................................................

Legal Obligation to Report Work stoppages............................................................... 3

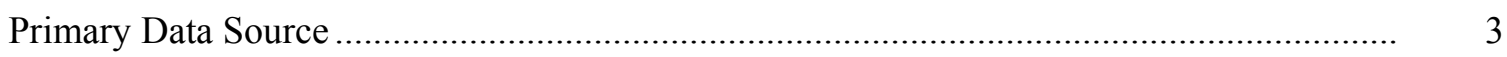

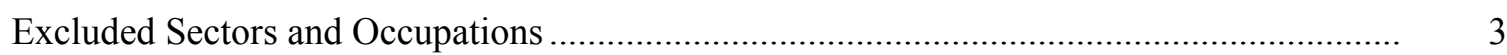

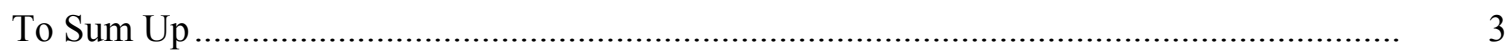

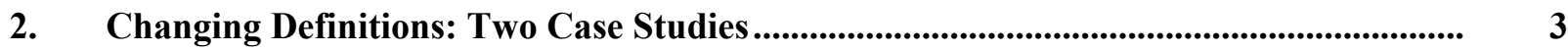

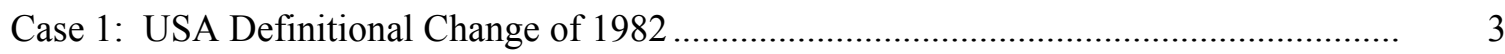

Case 2: Changes in the Treatment of Work Stoppages by Cause in Australia ..................... 3

3. A Preliminary Weighted 'Global' Work Stoppages Index: 1960-2002 ........................... 3

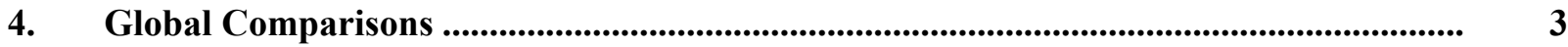

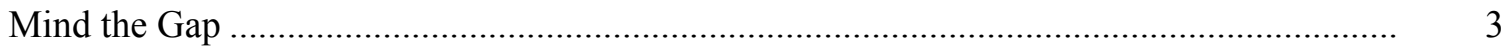

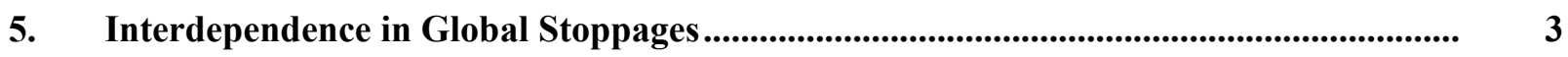

Stationarity Tests of the Global Indexes ................................................................... 3

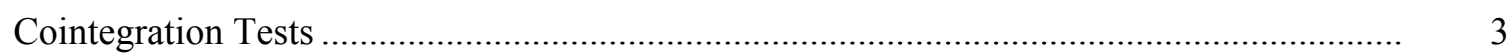

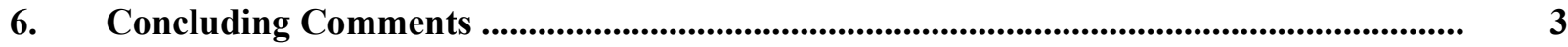

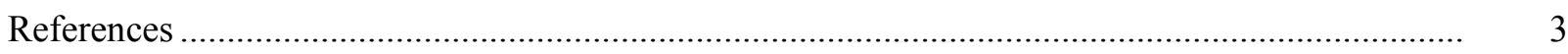

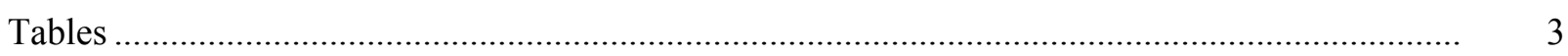

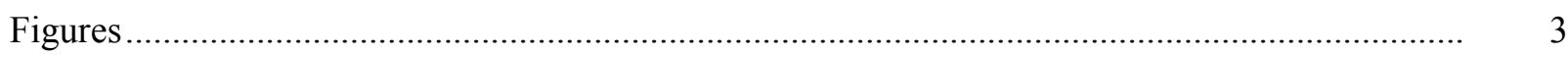




\section{Abstract}

This paper explores trends in international work stoppages over the last 4 decades or so. International collection practices are compared, extending the comparisons made in Fisher (1978), Sweet and Jackson (1977), Walsh (1983), Creigh and Poland (1983) and Monger (2004) to include 18 non-OECD countries. Two case studies of definitional changes are analysed for the United States (USA) and Australia. In the case of the USA, the impact of the 1982 definitional change is reviewed, and estimates are made of USA small-scale stoppages for the period 1982-2002. These data are incorporated in a GDP-weighted 'global' work stoppages index covering the period 1960-2002. Comparisons are made between various 'global' work stoppages indexes and individual countries that make up the index. Comparisons are also made, although more limited, between other economies that have limited data runs. Tests for interdependence are carried out (i) between stoppages in the USA and stoppages in the rest of the (non-USA) world and (ii) between stoppages in North America and stoppages in the rest of the (non-North American) world. Evidence of cointegration is found, suggestive of a long-term equilibrium relation between the major 'halves' of the global economy 


\section{Acknowledgments}

This paper was written with the support of the International Labour Office (ILO). The authors thank the ILO for its support and assistance in gathering data. We also thank David Kucera and Karen Taswell of the ILO for valuable comments on earlier drafts. The preparation of this paper commenced while the writers were Visiting Fellows at the Department of Economics, University of Wollongong in the first semester of 2004. We thank the Department for its support during this period.

The paper was completed at the authors' home institution, School of Finance and Economics, University of Technology, Sydney. We thank the School's research assistants and library staff for their assistance in gathering data.

The authors alone are responsible for the views expressed herein. In particular, neither the ILO nor any of its staff necessarily endorse, or are responsible for, the views expressed herein. 


\title{
Preface
}

There are relatively few statistics collected at the country level that shed light on the nature of freedom of association and collective bargaining rights and social dialogue. Three such statistics have been suggested in the Policy Integration Department's working paper "Measuring Decent Work with Statistical Indicators" (Anker et al., 2002) as well as the United States National Research Council's report Monitoring International Labor Standards: Techniques and Sources of Information (2004). These are the union density rate, the collective bargaining coverage rate and - the subject of the current paper - the strike activity rate.

Even leaving aside for a moment the problems of cross-country comparability and missing data, these statistics are not without problems in providing a picture of a country's freedom of association and collective bargaining rights and social dialogue. Regarding strike activity, instance, Anker et al. write that "in certain, circumstances, the absence of strike action could indicate the absence of the right to strike and weak social dialogue" (p. 57). Put in other words, there is an ambiguity as to whether more strike activity indicates stronger or weaker collective bargaining rights and social dialogue.

That said, there are indeed serious problems for strike activity data of cross-country comparability and gaps in coverage across countries and over time. An assessment of these problems and recommendations as to how to best remedy them are some of the key issues addressed in the current paper by L. J. Perry and Patrick J. Wilson, two leading researchers on international strike activity. Regarding cross-country comparability, the paper argues that these problems are minimized by using data on days not worked because of strike activity rather than on the number of strikes or the number of workers involved in strikes. The paper describes in some detail the serious problems with missing strike activity data, with a large number of countries not collecting these data and a good many others collecting these data only intermittently. The paper makes recommendations as to the most cost-effective means of improving the collection of strike activity data, recommendations based on the authors' analysis of the sensitivity of the data to differences in the scope of coverage, such as by the number of workers involved in a strike.

The paper also describes trends in global strike activity in the 1960 to 2002 period, particularly the downward trend beginning around 1970. For these purposes, the authors construct for the first time a "Global Work Stoppages Index" as well as sub-indexes broken down by country groups. The authors find patterns of long-run parallel movement in these sub-indexes, consistent with the view that strike activity across different groups of countries might be causally linked.

\author{
Peter Peek \\ Manager \\ Statistical Development and Analysis Unit \\ Policy Integration Department
}

October 2004 


\section{Measuring International Work Stoppage Statistics}

Work stoppage statistics (i.e. statistics on strikes and lockouts) began being collected in Austria, Belgium, Denmark, France, Germany, Italy, Japan, the United States (USA) and the United Kingdom (UK) in the late $19^{\text {th }}$ century. By the early $20^{\text {th }}$ century, government statistical departments in most industrialised countries and a number of developing countries and territories (India, Palestine, the Philippines and South Africa) were collecting stoppage statistics. In 1926 the International Labour Organization (ILO) sought to encourage member countries to standardise collecting practices in terms of definitions and methodologies. ${ }^{1}$ However, the practices established by the pioneer collecting countries have been slow to change. And even though some degree of standardisation in collecting and compiling practices has been achieved over the years, considerable differences remain. $^{2}$

From the earliest times of collecting stoppage statistics, differences in collection practices, definitions and procedures have existed. For example, early USA collections counted the number of stoppages and, for a time, the number of workers involved in stoppages, but not the average duration of stoppages or the number of days not worked (DNW) due to work stoppages. ${ }^{3}$ Similarly, Japan initially collected only data on the number of stoppages and workers involved until 1924 when DNW data were included. ${ }^{4}$ Most early European collections, on the other hand, did include estimates of DNW.

Stoppage statistics frequently appeared with gaps (i.e. missing observations). Thus there were no formal collections in the USA between 1906 and 1913; estimates of DNW did not appear for the USA until 1927. ${ }^{6}$ Wars, social turmoil and political oppression, of course, have the potential to affect both the number of stoppages and the recording of stoppages. There are frequently gaps in the time-series data during these periods of turmoil and

${ }^{1}$ The International Labour Organization (ILO) had held a number of conferences between 1923 and 1926 designed to standardise the collection of industrial disputes statistics. See Sweet and Jackson (1978) for commentary on these conferences.

${ }^{2}$ The ILO's continuing work on standardising and improving collecting and compiling methodologies led to the adoption of a resolution concerning statistics on strikes, lockouts and other action due to labour disputes by the ILO: Fifteenth International Conference of Labour Statisticians in 1993. A number of countries have already adjusted their methodology for statistics on strikes and lockouts so as to align them with the ILO: Fifteenth International Conference of Labour

Statisticians resolution, including Australia, the United Kingdom, and many of the transition countries.

${ }^{3}$ Different expressions are used to describe 'days not worked' due to strikes and lockouts. They include working days lost, man days lost, days idled, time lost and so on. The ILO: Fifteenth International Conference of Labour Statisticians preferred expression is 'days not worked'. Likewise work stoppages are often referred to simply as stoppages, strikes, strikes and lockouts, disputes and industrial disputes. The ILO: Fifteenth International Conference of Labour Statisticians preferred 'strikes' and 'lockouts'. However given that many countries (e.g. USA, Canada, New Zealand, Singapore, Hong Kong SAR (China)) still use the expression 'stoppages', this paper will also.

\footnotetext{
${ }^{4}$ See Gordon (1988) and Mitchell (2003a).

${ }^{5}$ See Mitchell (2003b).

${ }^{6}$ See Mitchell (2003c).
} 
conflict. For example Austria, Belgium, Finland and South Africa have, according to ILO records, gaps during the years of World War I (1914-1918), as do Belgium, Finland, France, Germany, Italy, Japan, the Netherlands and Norway (among others) during the years of World War II (1939-1945).

The problem of there being gaps in the information has, in many respects, been magnified in more recent years. Consider the annual data for DNW due to work stoppages for the period 1980 to 2002. For the ILO-identified regions of Africa, Asia, Europe (excluding former Soviet Union states and its allied states), North and Central America, Oceania and South America, the proportion of missing original annual observations are respectively: $72 \%, 27 \%, 10 \%, 35 \%, 62 \%$ and $43 \%{ }^{7}$

No doubt, some of these missing observations are due to major political change, wars and other disruptions. Other missing observations are due to individual countries deciding to cease collecting and publishing data altogether, as has recently been the case with Greece, for example. ${ }^{8}$ However, once allowance is made for these sorts of considerations, the fact remains that the number of missing observations poses a sizable and significant problem to labour market researchers and policy makers.

The pervasive problem of there being missing observations for most countries puts severe constraints on any analysis that seeks to make international comparisons and/or develop a global perspective on work stoppages. In this paper, we will initially confine our international comparisons to those countries, 38 in total, that have either a full set, or a near-full set, of aggregate work stoppage statistics for the period 1960 to 2002 . This period is chosen because it represents a period during which considerable change occurred in the number of work stoppages in many countries. The large number of countries excluded from the initial comparative review is determined by them having a large number of missing observations. There seems to be little point in discussing the comparative collecting and compiling methodologies of countries that do not in fact have a reasonable run of statistics in the first place.

Table 1 identifies those 38 countries that have either full or near-full data sets for the period under review. Even among these countries there are difficulties. For example, Bangladesh did not come into existence until 1971, Germany re-unified in 1990 (with stoppages statistics 're-unified' after 1992), quite a number of countries, mainly less developed ones, have occasional missing observations, and other countries (including France) have not yet posted data for 2002. One country, Nigeria, has qualitative descriptions of trends in its DNW due to stoppages for the period 1999 to 2002, necessitating the authors to estimate DNW due to stoppages based on limited quantitative estimates of the number of stoppages that correlate with DNW. ${ }^{9}$ A reasonable case could be mounted for excluding Nigeria from the picture. However, given that it is the most

7 These percentages are calculated for DNW from the data available at the ILO web site (http://laborsta.ilo.org/) and from various editions of the ILO's Year Book of Labour Statistics.

\footnotetext{
${ }^{8}$ See Monger (2004).

${ }^{9}$ The ILO no longer publishes Nigerian work stoppages. The last year for which data are published in the ILO's Year Book of labour Statistics is 1993. Nigerian sources are difficult. The source of Nigerian data after 1993 is the Central Bank of Nigeria, Annual Report and Statement of Account.
} 
populous country in Africa, and given also that African countries are grossly underrepresented in the table, it was decided to include Nigeria in the review. ${ }^{10}$

The comparisons we make on how different countries collect and define work stoppages are made in reference to the following considerations:

- The minimum criteria for inclusion (e.g. the minimum duration of a dispute)

- Whether strikes and lockouts are counted separately

- Whether political strikes are included

- Whether workers indirectly involved in disputes are counted

- The minimum collection period (monthly, quarterly or annual)

- Whether reporting disputes is required by law

- The sourcing of data (media reports, employers and/or unions)

- Whether certain sectors are excluded from the tally (eg disputes in public administration)

Comparisons of collection practices, of a more recent vintage, have been made by Fisher (1973), Sweet and Jackson (1977), Walsh (1983), Creigh and Poland (1983) and Monger (2004). ${ }^{11}$ These studies all focus on developed OECD economies, which of course is understandable because OECD economies typically have relatively detailed data. However in this paper, we will seeks to extend the range of countries under review to include at least a selection of African, non-OECD Asian, and Central \& South American countries. This may give a broader perspective on global changes in work stoppages statistics, both the reporting methodologies and the trends in the data themselves.

As will be seen, all the countries reviewed in Table 1 have somewhat idiosyncratic collection practices. Nevertheless, there are commonalities and arguably some scope for broad comparisons.

\footnotetext{
${ }^{10}$ Additionally, Nigeria experienced a dramatic rise in DNW due to stoppages in the mid 1990s, as noted by, for example, Egwaikhide and Isumonah (2001) and Oguejiofor (2004). Arguably this information, even if imperfectly measured, should not go un-noted.

11 The official UK publication: Labour Market Trends makes annual comparisons of OECD economies. Monger (2004) is the latest of these. The ILO is the principal source of all information on comparative statistics. See in particular ILO (1993, 1999 and 2004). These data, and a wealth of other information, are readily available at http://laborsta.ilo.org/
} 


\section{Minimum Criteria}

The minimum criteria for inclusion in a national collection of work stoppage statistics varies widely from no minimum criteria, as is the case for 13 of the countries in Table 1, to 1000 workers involved. Among the largest 8 economies - the 'Big- 8 ' - in Table 1 (composed of OECD Big-7: the USA, Japan, Germany, France, Italy, the UK and Canada, plus India), only Italy and Japan have no minimum criteria. In 1982 the USA introduced a new minimum threshold criterion. The new minimum threshold was a minimum of 1000 workers involved in a stoppage. This radically altered the number of DNW due to work stoppages in the post-1981 period. The earlier threshold criteria had been 6 workers. The extent of the reduction in the number of DNW recorded is in the vicinity of $40 \%$. This will be further discussed below.

Many different minimum criteria for exclusion have been adopted by different countries, with for example Denmark, Germany and the UK adopting a (more or less) 100 DNW criterion, while Canada and India have a threshold of 10 workers involved. Table 1 summarises the differences.

Past reviewers (for example: Fisher (1978), Sweet and Jackson (1977), Walsh (1983) and Creigh and Poland (1983)) of international differences in threshold criteria point out that aggregate statistics on work stoppages are typically dominated by larger disputes. Smaller and briefer disputes usually do not determine the overall shape of the data over time, nor do smaller disputes account for a numerically large proportion of days not worked due to stoppages. Thus, provided there is a focus on aggregate days not worked, as opposed to just the number of disputes or workers involved, these differing threshold criteria when relatively small, though clearly not ideal, probably do not make a great deal of difference. ${ }^{12}$ However, when the threshold differences are quite major, as is singularly the case with the USA definitional change of 1982, comparisons may become more problematic.

\section{Strikes or lockouts}

Work stoppages involve strikes and lockouts. Strikes involve employees withdrawing their labour. Lockouts involve employers refusing to employ current employees. Most countries do not distinguish between the two; and the ILO does not publish separate numbers for strikes and lockouts.

One reason for the preference for combining the two, is that it may be difficult to make a clear-cut decision as to whether a dispute is essentially a strike or a lockout. This is because elements of responsibility for the stoppage of work rests with both parties involved in the dispute.

\footnotetext{
12 This of course presupposes an interest only in the broadest measure of work stoppages, i.e. the number of days not worked. If interested in the number of stoppages or the number of workers involved or any other dimension that requires accurate estimates of these measures (such as the average duration of stoppages), then differing minimum criteria may seriously frustrate attempts to make international comparisons.
} 
Fisher (1973) noted that:

'It is extremely difficult, even for those actually involved, to distinguish cause and effect in the origin and generation of disputes that result in stoppages of work. A stiffer attitude by management over proposed rates of pay, or over rates of utilisation of newly installed equipment, may be followed by a strike. Did management deliberately provoke this, or was it a rash, or well-judged, response by workers? If the provocation was that of the employers why was it the worker who took the positive step? Clearly one cannot simply maintain that strikes are always the result of workers' reaction or that lockouts are the only occasions when employers have taken a decisive stand.'

Most countries from the selection in Table 1 do not distinguish between strikes and lockouts in their collections. In other words, strikes and lockouts data are combined. Of the 'Big-8' countries in Table 1, Canada, Japan, Germany and India do provide separate data though these separate data are not published by the ILO. In the case of Germany, Walsh (1983) notes that the proportion of disputes attributed to lockouts is atypically high accounting for around 44 per cent of all disputes for the decade ended 1981. He argues that 'German employers have been more disposed to using the lockout to counter employee claims than is the case in other countries, with lockouts occurring usually at the same time as a strike (as a counter measure to the strike). In other countries these sorts of lockouts are virtually unknown, and in France they are considered in most cases to be illegal. ${ }^{13}$

The suggested relatively minor role of lockouts for various European economies does not extend to India, at least during more recent years. Dutt (2000) points out that for India, lockouts, as a proportion of total stoppages, grew particularly during the 1990s. These observations also apply to more recent years, with the ratio of DNW due to lockouts accounting for about two thirds of all stoppages for the period 1999-2002. ${ }^{14}$ Dutt attributes the relative rise of lockouts in India to the implementation of reformist market-oriented policies that have empowered employers and management to act more aggressively towards labour. The fact that lockouts have become increasingly important in India, within a general context of declining total stoppages rates, implies that strikes have become much less prevalent than the aggregated data might, at first glance, suggest. It would be of interest to see if the Indian experience is duplicated elsewhere, at least for that small band of countries that publish these data.

\section{Political strikes}

A political strike can be viewed broadly as being one where the strike is not specifically related to work and related arrangements between employers and employees. A political strike is more likely to be related to broader social issues, such as government policy on health, social security or defence issues. Sometimes such political issues may have implications, nevertheless, for the material wellbeing of the worker. For example a protest strike about the provision of public sector health benefits may be designed to pressure government into maintaining the purchasing power of existing wages.

Nevertheless, a political strike would clearly be distinguishable from a strike directed at an employer designed to pressure the employer, say, to increase wage rates. The employer can address the issue raised when being pressured by the strikers for a wage increase, but an

\footnotetext{
${ }^{13}$ See Walsh (1983, p. 16) and Kennedy (1980, p. 181) whom Walsh (1983) cites. See also Oxnam (1975) who argues similarly. Lockouts in the UK are, according to Walsh (1983, p. 126), 'reckoned to be small in practice'.

${ }^{14}$ Labour Bureau, Government of India: http://labourbureau.nic.in/ID2Kmp.html. For 2003 the proportion DNW attributable to lockouts was over $90 \%$.
} 
employer has no power to address workers' grievances related government policy on health care or military spending. ${ }^{15}$

Of the countries in Table 1, twenty include political strikes in their collections, thirteen exclude them and, in some countries, such as South Africa, political strikes are included in the aggregate but:

\begin{abstract}
'only when, at the workplace, demands are made for political or protest reasons coupled with the demands that are connected purely with industrial relations issues concerning terms and conditions of work; not when employees take to the streets and political or protest demands are made en masse, 16
\end{abstract}

Major economies that include political strikes are Canada, France, Germany, Italy and Japan. Major economies that exclude political strikes include India, the USA and the UK.

Walsh (1983) notes that Italy had (during the earlier 1970s) a large proportion (21\%) of political strikes He notes that Italy's experience is exceptional when compared to various other European countries, but warns that failing to include political strikes in the total tally could result in a significant underestimation of disputes. He argues that:

\begin{abstract}
'There are strong grounds for including such action when it occurs, despite the insistence in some countries that stoppage statistics should be confined to those disputes concerned with the terms and conditions of work. Though most protest actions on a large scale (for example, national strikes) may ostensibly seem politically motivated, in most cases there will be underlying causes fundamentally concerned with terms and conditions of work. A national protest stoppage over, say, a wage freeze is primarily concerned with the pay of individual strikers and its appearance as a political strike will arise out of the direction of the protest towards the instigators of the measure, namely the government' (p. 22)
\end{abstract}

Against this view, it can be argued that if there are mass stoppages over, say, "purely political' issues, such as public health services, or education or defence or environmental policy or policing standards, then incorporating these stoppage statistics may exaggerate the extent of workplace discord. As noted earlier, there is little an individual employer can do to address these sorts of political grievances, so it is arguably inappropriate to incorporate these sorts of stoppages with other stoppages clearly linked to workplace issues.

In the final analysis, it might best be recommended that all political-stoppages statistics be counted, but that these stoppages be clearly categorised in terms of their workplace implications so that those that have little or nothing to do with workplace issues are distinguished from those that do. It would then be up to users to employ these data in a way that best suits their requirements.

\title{
Workers Indirectly Involved in Work Stoppages
}

Workers indirectly involved in a work stoppage are estimated for 19 of the 38 countries in Table 1, and not estimated in 15 countries.

15 It may be the case that general strikes for general wage increases by (say) an overarching legislative authority may not be addressed by the individual employer, but by a government legislative authority. In this case the strike would not be classified as political even though it might be seen to have a considerable political element within it.

16 ILO: Sources and Methods: Labour Statistics, Vol. 7: Strikes and lockouts (2004). (http://laborsta.ilo.org/). 
Among the major economies to include estimates of workers indirectly involved are Canada, France, India, the UK and the USA. Major economies not to have such estimates include Germany, Italy and Japan. Clearly the latter countries will have relatively low aggregate work stoppage statistics. This difference in terms of workers involved in work stoppages may be in the vicinity of one fifth according to Walsh $(1983$, p. 18, 54). However, most countries do not split the number of DNW according workers being directly and indirectly involved. Given that workers indirectly involved in disputes would likely be affected on average for a shorter period of time, the impact on DNW is likely to be proportionally smaller than the impact on the number of workers involved. ${ }^{17}$

We should be careful here to note that workers indirectly involved are only those workers in the same workplace as the workers directly involved in the stoppage. Workers prevented from working by the secondary effects of the stoppage, i.e. who are working in establishments outside those involved in the stoppage, are not counted, with the apparent single exception of Bangladesh which counts workers directly and indirectly involved and '... workers rendered idle in economic units other than those directly involved in the strikes' ${ }^{18}$ However, Bangladesh confines its collection to the manufacturing sector alone.

\section{Minimum Collection Period}

Seventeen of the countries in Table 1 collect and publish statistics on a monthly basis. All of the big- 8 collect and publish dispute statistics on a monthly basis, with the single exception of Germany. High frequency data, however, are normally inaccessible to researchers who are not physically located in the country for which data is sought. This is because these data are not generally published and dispersed internationally. Indeed, it can be difficult enough for locally-based scholars to develop a high frequency long-term data set.

The OECD has published, at various times, DNW series on a monthly basis in Main Economic Indicators. However, this is merely one of many high frequency series that are of interest to labour market researchers. Moreover, currently the OECD only publishes monthly data for four of the big-7 OECD countries: Canada, Italy, the UK and the USA. Monthly data for Japan and France must be tracked down via local primary source searches.

From Table 1, one country, the Philippines, is reported to publish weekly dispute statistics. Three countries publish quarterly data, while 13 publish annual data only. Amongst these are Austria, Denmark, Korea, Malaysia, South Africa, Sweden and Switzerland.

\footnotetext{
${ }^{17}$ Note also, when it comes to the day-to-day practicalities of estimating the number of workers involved directly in a strike versus the number indirectly involved, it may be difficult to distinguish between the two, so that as a consequence the two may simply be lumped together. This would be more particularly the case during a lockout. The ILO: Fifteenth International Conference of Labour Statisticians, resolution recommends that "Each worker involved directly or indirectly at any time during the action should be counted in the number of workers involved, whether the involvement was for the full duration or only part of it."
}

18 ILO: Sources and Methods: Labour Statistics, Vol. 7: Strikes and lockouts (2004). (http://laborsta.ilo.org/). 
Besides providing a much richer source of information, one of the advantages of publishing high frequency (monthly and quarterly) data, is that it facilitates modelling stoppages in, perhaps, systems of equations in which other quarterly observations are applied. ${ }^{19}$

\section{Legal Obligation to Report Work stoppages}

Table 1 indicates that most countries (19) do not have laws making it compulsory to report disputes to some or other government authority. Twelve countries do have such laws, while 3 have laws that partly require reporting (e.g. government sector stoppages). It would not seem unreasonable to assume that, in those cases where reporting stoppages is not compulsory, there may be a degree of under-reporting, particularly with reference to smaller disputes and unofficial or illegal strikes.

There is some evidence that, for Sweden and the UK, substantial under-reporting occurs ${ }^{20}$, particularly for smaller stoppages and for smaller establishments. Notwithstanding this shortcoming, Creigh and Poland (1983, p. 87) note that '... the official stoppage statistics relating to working days lost prove to be very accurate, largely because the large and long stoppages, which are the most likely to be recorded, account for most days not worked'. This is an important observation, and it is one made earlier in this paper in reference to differing selection criteria. So long as the focus of attention is on DNW, rather than the number of stoppages or the number of workers involved in stoppages, and so long as the dimensions of larger-scale or major stoppages are accurately measured, then the less accurate collection of small stoppages will not do much damage to the aggregate estimate of DNW. This is simply because, these relatively small-scale stoppages do not account for a large proportion of total DNW.

\section{Primary Data Source}

The modes of data collection vary quite markedly between countries presented in Table 1 . What perhaps is most evident is the tendency to rely quite heavily on media reports for information. Media reports are typically followed up officially, and it is upon this basis that the statistics are generated. Clearly, for large-scale disputes that receive some prominence in media reports, we might be reasonably confident of getting an accurate estimate of days lost due to disputes. But for smaller, less publicised, disputes, we can be less confident.

Another feature of the collection practices is the greater reliance on employer records than union records. Employers are perhaps typically in a better position to measure absences, and the reasons for these absences, than are unions. This is not always the case, though. Some countries, Austria, Malaysia, Peru, the Philippines and Switzerland draw heavily from unions as their primary source of information. Police involvement occurs in India, Italy, Mauritius, and Puerto Rico (USA).

\footnotetext{
${ }^{19}$ See for example Morris and Wilson (1999) and Perry and Wilson (2001, 2003).

${ }^{20}$ See Kopi (1981), Kelly and Nicholson (1980) and Jackson (1987).
} 
The fact that different primary sources are used in different counties, coupled with the often voluntary nature of the reporting stoppages, underlines the considerable differences and potential plasticity of national statistical collections. As was pointed out earlier in this paper, the fact that most stoppages series are dominated by a small number of relatively large work stoppages, assists in the collection process and assists in reducing the impact of various differences in collection practices, at least with respect to measuring days not worked.

\section{Excluded Sectors and Occupations}

For most countries no particular occupational groups or sectors or geographic locations are excluded in the tally of work stoppages. For the countries in Table 1, exceptions include France, Germany, New Zealand (prior to 1988), Peru, the Philippines and South Africa, which to varying degrees exclude work stoppages in public administration and/or parts of the public sector. South Africa, for example, excludes work stoppages in public administration and various other parts of the public sector such as all educational institutions. Other countries to exclude sectors are Bangladesh that only records work stoppages in the manufacturing sector, India which excludes 'industries performing services relating to sovereign functions, ${ }^{21}$ and Israel which excludes work stoppages in the army and non-military security forces. One country not mentioned in Table 1, Argentina, for many years reported (albeit erratically) on disputes solely in the country's capital city, Buenos Aires (excluding even the 19 surrounding municipalities). ${ }^{22}$

\section{To Sum Up}

From the foregoing discussion, it is clear that there are many differences in the collecting and compiling practices of different countries. An obvious implication is that considerable caution needs to be exercised when making comparisons internationally. Indeed, even domestic trends need to be viewed cautiously when there are excluded sectors (such as public administration), excluded stoppages (such as political strikes), excluded workers (such as those workers indirectly involved), excluding selection criteria (such as excluded relatively small-scale disputes) and definitional changes (such as occurred in the USA in 1982 when only major stoppages were to be counted).

Given that it is not possible to standardise information (except perhaps marginally) for different countries and for different periods during which collection practices may have changed, researchers are faced with considerable difficulty in making comparisons. However, when comparisons are made, as they inevitably are, fewer problems are likely to arise when (i) trends are compared and (ii) focus is given to days not worked (rather than, say, to the number of disputes or the number of workers involved). ${ }^{23}$

21 ILO: Sources and Methods: Labour Statistics, Vol. 7: Strikes and lockouts (2004). (http://laborsta.ilo.org/).

${ }^{22}$ See McGuire (1996, p.129), who gives an overview of the complexities and inconsistencies in the Argentine collection and reporting of work stoppage statistics.

${ }^{23}$ Most researchers favour DNW as the best overall measure of work stoppages. This view is encapsulated in Creigh and Poland (1983, p. 56) who argue that DNW is '... clearly likely to provide the best single comparative yardstick ... because as Turner (1969) originally argued, the bulk of days lost in each country are accounted for by a small number of major stoppages which will be recorded irrespective of differences in definitions and collection methods' 
Table 1 has summarised the many definitional and collecting differences in the data from our collection of 38 countries. And while these differences must be recognised as being an impediment to comparisons, it is the central argument of this paper that the more serious problem is the vast number of missing observations. Even some of European countries have gaps in their collections.

We strongly recommend that, even if the relevant agencies simply record stoppages in major disputes - a relatively easy and inexpensive exercise - this would at least provide a basis for judging changes in the industrial relations environment over time. Some data, imperfect and crude as it may be, is much more preferable than none; and currently there are for many countries more gaps in stoppages statistics than there are observations.

\section{Changing Definitions: Two Case Studies}

The previous section focused on differences in international collections and definitions used. This section will look at two case studies of definitional change, one relatively major, the other, relatively minor. These case studies serve the purpose of illustrating how definitional changes can, in some instances, seriously affect the dimensions of a data set and frustrate the desire of researchers to have access to conceptually consistent data over a reasonable time frame. However, it will also suggest that often these problems can, at least in some cases and to some degree, be worked around.

\section{Case 1: USA Definitional Change of 1982}

In 1982 the USA Bureau of Labor Statistics announced that 'due to budget stringencies' the collection of work stoppage statistics would be changed from counting all disputes involving 6 workers or more to counting all disputes involving 1000 workers or more and lasting at least one full shift. ${ }^{24}$

The Bureau gave backdated annual estimates of work stoppages involving 1000 workers or more for the period 1947 to 1981 . The estimates included (i) the number of stoppages, (ii) workers involved and (iii) days idle (equivalent to DNW). These data can be compared with the discontinued series of work stoppages involving 6 workers or more. Comparing the simple averages for 1947-81 of the three measures of stoppages we get the following outcomes of going from the old 6-workers definition to the new 1000-workers definition:

(i) The number of work stoppages falls from 4378 to 296 (a fall of 93\%!).

(ii) The number of workers involved in work stoppages falls from 2.1 million to 1.4 million (a fall of $31 \%$ ), and

(iii) The number of days idled falls from 3.4 million to 2.4 million (a fall of $29 \%$ ).

\footnotetext{
${ }^{24}$ See Monthly Labor Review, May 1982, p. 102 and June 1982, p. 111 (US Department of Labor, Bureau of Labor Statistics).
} 
These results indicate that most of the major changes in total DNW due to stoppages came from relatively large disputes rather than small disputes. ${ }^{25}$ There were clearly many more small disputes than large disputes, but the small disputes do not, by and large, determine the overall shape of the total data over time. This is more clearly illustrated in Figure 1, which charts 'time lost', the number of DNW per 1000 non-agricultural employees. ${ }^{26}$ The figure indicates that there is a strong parallel relation between total time lost and time lost in large-scale disputes. The correlation coefficient is 0.99 . On the other hand, the association between time lost due to the small disputes and total time lost is much looser, with a correlation coefficient of $0.58 .^{27}$

How did the relation between total stoppages, large-scale stoppages and small-scale stoppages change over the period 1947 to 1981? Figure 2 assists in answering this question. It charts (i) the ratio of time lost in large-scale stoppages to total time lost and (ii) the ratio of time lost in small-scale stoppages to time lost in large-scale stoppages. Over the period 1947-81 small-scale disputes became relatively more important, so that for much of the decade-ended 1981 the proportion of small-scale disputes to large-scale disputes hovered around the $60 \%$ mark.

Given the substantial impact of the definitional change on time lost due to work stoppages, we now attempt to estimate what the number of disputes might have been if there had not been the definitional change in 1982. Effectively what we are seeking to estimate is the number of 'days idled' by small disputes. We have the official numbers of large-scale disputes. If we can estimate the number of small-scale disputes, then add those estimates to the official large-scale dispute numbers, then that will provide us with an estimate of total disputes.

Perry and Wilson (2001) estimated the total of small- and large-scale disputes by simply grossing up the large-scale disputes by a constant multiple. The multiple was the ratio of total (small-scale plus large-scale) disputes to large-scale disputes during the period 197681. That ratio was about 1.4 to 1 . Arguably, a shortcoming of that approach is that it generates (implicitly) estimates of small-scale disputes that are as volatile as large-scale disputes. That result is counter factual, however, as Figure 1 indicates that small-scale disputes were much less volatile than large-scale disputes during the period 1947 to 1981 . An alternative approach is to estimate the number of small-scale disputes econometrically. To do this, we hypothesise that the ratio of (i) small-scale disputes per employee to (ii) large-scale disputes per employee, is potentially affected by five variables ${ }^{28}$. The first explanatory variable is the number of large-scale disputes per employee. Here we argue that, since large scale disputes have a defining impact on total disputes, while small-scale disputes are relatively more stable over time, an increase in the number of large-scale

${ }^{25}$ The results also indicate that the workload of reporting relatively small-scale disputes was indeed dramatically reduces, as the number of stoppages fell by $93 \%$.

\footnotetext{
${ }^{26}$ Denominators other than non-agricultural employees could alternatively be used; for example, the labour force, population, unionists etc. The overall results are unaffected.

${ }^{27}$ The correlation coefficient for time lost in (i) large-scale stoppages and (ii) small-scale stoppages is 0.49 .

${ }^{28}$ Broadly speaking the macroeconomic variables employed in this model are those that have been found to be relevant in other studies of the macroeconomic determinants of aggregate work stoppages. See, for example, Perry (1980), Morris and Wilson (1999) and Morris (2003). Note that, in this particular case, the limited number of observations acts as a constraint on the number of explanatory variables employed.
} 
disputes will tend to generate only a muted parallel response in small-scale stoppages, and thus the ratio will tend to fall. Hence we hypothesise an inverse relation.

The second explanatory variable is hypothesised to be trade union density - the ratio of union members to total employees (or some other labour market standardising unit, such as the total labour force $)^{\mathbf{2 9}}$. Here we hypothesise that as union density increases, the ratio of small to large DNW tends to decline, on the grounds that higher union density might be expected to enhance the capacity of unions in general to mount larger-scale campaigns, while lower density would tend to limit unions to smaller-scale campaigns. Hence an inverse relation is envisaged.

The third explanatory variable is the unemployment rate ${ }^{30}$. Here we hypothesise that while an increase in the unemployment rate will have a negative effect on both large- and smallscale disputes, to the extent that small-scale disputes may reflect smaller-scale union operations and employment arrangements, a greater sensitivity to competitive labour market pressures may be present. This will, in turn, make smaller-scale disputes relatively more sensitive than larger-scale disputes to unemployment rate changes. Thus an increase in the unemployment rate might, if this is the case, have the effect of reducing the ratio of small- to large-scale disputes. Hence an inverse relation is envisaged.

The fourth explanatory variable is inflation ${ }^{31}$. Here, if small-scale disputes are more sensitive to inflation than to large-scale disputes, then the relationship will be positive (and vice versa). To the extent that large scale disputes might be generally thought to be associated with well-informed, larger-scale union operations, one might expected greater sensitivity here to price level changes. Thus, if price level changes are responded to more aggressively by larger well-informed unions than by smaller operations, we might expect a negative relation between inflation and the ratio of small- to large-scale stoppages.

The fifth explanatory variable is real GDP. To the extent that larger-scale stoppages reflect the operations of larger-scale unions, one might expect greater sensitivity on their part to increases in real GDP. Under these circumstances, a negative relation between the smallto-big- stoppage ratio and real GDP might be expected. On the other hand, it may be that smaller-scale industrial actions are more effectively pursued than large-scale campaigns when there are relatively favourable underlying economic circumstances (i.e. strongly rising real GDP). Under these circumstances, a positive relation between the small-to-big dispute ratio and real GDP might be expected. Thus the relationship between real GDP and the small-to-big- stoppage ratio may be either positive or negative. ${ }^{32}$

The general form of the relation can be summarised as below:

$(S S / S B)=f(S B, D, U, P, Q)$

${ }^{29}$ The argument that stoppage rates in general are affected by union density has been advanced in Snyder (1977), Kaufman (1981), Freeman and Medoff (1984), Booth (1985), Naylor (1989), and McCammon (1993) among others.

${ }^{30}$ The argument that stoppage rates in general are affected by the unemployment rate and/or other business-cycle-sensitive variables has been advanced in Hansen (1921), Griffen (1939), Yoder (1940) and Ashenfelter and Johnson (1969) among others.

${ }^{31}$ The argument that stoppage rates in general are affected by inflation has been advanced in Hansen (1921), Rees (1952), Knowles (1952), Kaufman (1981) and Wallace et al. (1988) among others.

${ }^{32}$ Indeed the same comment might also be made for the second, third and fourth variables, as alternative rationales might find support. The signs of these relations are not central to the model. 
In the above, $S S$ is the number of DNW in small-scale stoppages per worker, $S B$ is the number of DNW in large-scale stoppages per worker, D is union density, $U$ is the unemployment rate, $\mathrm{P}$ is the price level, $\mathrm{Q}$ is real GDP and $f$ refers to the functional form of the equation.

Assume further that the above general relation takes a log-linear form as below:

$$
\ln (S S / S B)=\mathrm{a}_{1} \ln S B+\mathrm{a}_{2} \ln D+\mathrm{a}_{3} U+\mathrm{a}_{4} \ln P+\mathrm{a}_{5} \ln Q
$$

In the above, 'In' refers to the natural log operator. We have commented on the signs of the coefficients in the above discussion. If we further assume that $-1<\mathrm{a}_{1}<0$, then solve the above equation for $S S$ and totally differentiate ${ }^{33}$, we get:

$$
\Delta \ln S S=\left(\mathrm{a}_{1}+1\right) \Delta \ln S B+\mathrm{a}_{2} \Delta \ln D+\mathrm{a}_{3} \Delta U+\mathrm{a}_{4} \Delta \ln P+\mathrm{a}_{5} \Delta \ln Q
$$

In the above equation $\Delta$ is the first difference operator. Note also that since $-1<\mathrm{a}_{1}<0$, the coefficient for the first explanatory variable, $\left(a_{1}+1\right)$, will be positive.

In estimating the above relation we found that all of the variables (as they appear in the equation) are stationary (i.e. stationary as the first differences of logs), with the exception of the unemployment rate which is stationary in levels. We thus entered the $\Delta U$ variable as $U$ and $U_{-1}$. There were also allowances for possible lags etc. The preferred equation for $\Delta \ln S S$ is summarised in Table $2 \cdot{ }^{34}$ Based on this equation we estimated the sum of (hypothesised and extrapolated) small-scale stoppages and (officially enumerated) largescale stoppages. The numbers are reproduced in Table 3. Caution must of course be counselled in the use of these data as they are essentially speculative.

Concluding this section, a number of general observations are made. First, radical definitional changes, such as the USA 1982 definitional change, can radically alter the shape and information content of the new-definition material in comparison to the olddefinition material. In this section we have merely identified some of the myriad changes wrought by the definitional change. We have not considered the impact on stoppages by industry or stoppages by state, for example. We have focussed only on the aggregate data. Secondly, we find the justification for curtailing the survey of stoppages, namely budgetary constraints, curious. While it may be understandable for less-developed countries to make major economies in the collection of these data, that the most powerful economy in the world should need to so economise, is most puzzling. The USA managed to collect these data during war time and the devastating Great Depression, it seems incongruous that it cannot muster the resources to gather the data today. Finally, we note that even though the new collection practices are substandard, they do nevertheless have value and offer crucial insights into the USA industrial relations environment. The more pressing problem with global stoppage statistics is not that they are substandard (which they often are), but that there are very often either no observations at all or an inordinately large number of missing observations. Even if countries that currently fail to collect data

\footnotetext{
${ }^{33}$ We hypothesise an inverse relation the small-to-big stoppage ratio and the large-scale stoppages variable, with an elasticity coefficient value $\left(\mathbf{a}_{1}\right)$ less than zero, but greater than minus 1 .

${ }^{34}$ The challenge facing the current analysis was to develop a dynamic regression model that would encompass the insights offered in earlier empirical work in an attempt to build a parsimonious model of small-scale stoppages over a forward looking twenty year period. To facilitate model development, the authors used the PcGets software developed by Hendry and Krolzig (2001). This software was designed to model economic data when the specific form of the equation under analysis is not certain. In the present analysis degrees of freedom problems limited tests to a maximum of four lags. Degrees of freedom problems did not permit development of a VAR model.
} 
consistently were to make USA-style economies and focus only on large-scale disputes, this would at least provide this and future generations of researchers, policy makers, educators and, indeed, the wider community with some basis for understanding an important feature of their labour markets.

\section{Case 2: Changes in the Treatment of Work Stoppages by Cause in Australia}

Australian work stoppage statistics have been collected since 1913. They are categorised according to cause, among other things. The categories of cause have changed marginally over the years, but four broad categories of cause can more or less be isolated. These are work stoppages arising from:

(a) Wages, hours and leave issues,

(b) Managerial policy and physical working conditions issues,

(c) Trade unionism issues, and

(d) Other issues

Over the 91 years during which work stoppage statistics have been collected, disputes occurring over issues (a) to (d) have been $51 \%, 28 \%, 9 \%$ and $12 \%$ respectively of the total. ${ }^{35}$ Over the last 20 years the proportions have been $26 \%, 53 \%, 4 \%$ and $17 \%$ respectively. These percentages indicate the relative importance of remuneration issues (category (a)) has declined in recent years. Category (d) incorporates political stoppages. While category (d) has become relatively more important in recent years, it needs to be kept in mind that the overall number of stoppages has been on the decline.

The Australian Bureau of Statistics (ABS) has employed three approaches to recording stoppages by cause. Between 1913 and 1921 it published stoppages commencing each year by cause. Thus if a stoppage commenced on say 30 December and finished in March on the following year, then the stoppage would be assigned to the earlier year, rather than the later year. Between 1922 and 1978 the ABS published stoppages in progress each year by cause. Other compilations of Australian stoppage statistics are published as stoppages in progress. Thus between 1922 and 1978 it was possible to apportion accurately total stoppages statistics to appropriate causes.

From 1979 to the present, the ABS has published stoppages ending each year by cause. Thus if a stoppage commenced during November and finished on 1 January in the following year, then the stoppage would be assigned to the later year, rather than the earlier year, during which most of its impact was being felt.

Figure 3 charts the ratio of (i) the total number of days not worked due to stoppages by all causes to (ii) the total number of days not worked due to stoppages in progress. During the period 1913 to 1921, the average difference between stoppages commencing each year and in progress each year is 17\%. During the period 1979-2003 the average difference between

\footnotetext{
${ }^{35}$ All numerical values given in this section are based on data from Australian Bureau of Statistics, Industrial Disputes Australia, Catalogue Number 6321.0, and various predecessor publications.
} 
stoppages ending each year and in progress each year is $4 \%$. The basic reason for the lower average difference in measures of stoppages is attributable to the shorter duration of stoppages during the later period, thus making it easier to reconcile the two series. During the period 1913-1921 the average duration of stoppages was 15 days, whereas during the period 1979-2003, the average duration of stoppages was 2 days.

The basic problem with the ABS decisions to classify the causes of stoppages on a different chronological basis to other stoppage statistics, such as stoppages by industry and stoppages by state, is the issue of compatibility. If during the year a certain number of workdays are lost due to stoppages, then it is useful to know what proportion of the stoppages were attributable to various causal issues. As it stands, since 1979 and for 191321 , we cannot accurately assign to stoppages in progress the causal issues that were behind them. The easy solution is to publish the stoppages by cause information in terms of both work stoppages in progress during the year and work stoppages ending during the year. Then the user can decide which data set to employ.

\section{A Preliminary Weighted 'Global' Work Stoppages Index: 1960-2002}

In this section we attempt to develop a preliminary 'global' work stoppages index for the period 1960-2002. The index is described as preliminary because of the possibility of future data revisions changing the index. Having made this qualification, we do not envisage any major or dramatic changes in the overall shape of the index should such revisions materialise. The period 1960-2002 is chosen because it encompasses a period of time during which many of the world's economies experienced quite major changes in stoppage rates; moving typically from relatively low work stoppage rates during the early 1960 s to relatively high rates during the 1970 s and, to a lesser extent, the 1980 s, to relatively low rates during the 1990s. In addition, this period provides a timeframe free of global wars and a timeframe wherein a reasonable number of economies have complete or near-complete statistics on work stoppages.

There are two purposes in building this index. First it will give a measure of general global trends in so far as these trends are perceived to be of importance internationally. The second purpose of the index is to provide a benchmark against which other individual economies can be measured.

We earlier identified 38 countries with relatively complete collections of aggregate strike statistics for the period 1960-2002. These are the countries that make up the 'global' index. The work stoppages data for the 38 countries are combined in the following manner.

(a) For each country, the number of days not worked due to work stoppages per thousand members of the labour force is calculated. Table 4 column (i) records the 1960-2002 average work-stoppage rate for each of the 36 countries. These data are arranged in order of stoppage rates. The country with the lowest stoppage rate, i.e. the least strike-prone, is Switzerland which averaged 2 days not worked per annum for each thousand people in the labour force. The country with highest stoppage rate is Nigeria, recording an annual average of $1115 \mathrm{DNW}$ for each thousand members of the labour force.

It will be noted that the data are standardised in terms of the labour force rather than, say, the employees or unionists or the workforce (defined here as employees plus those unemployed). The reason for this is that the labour force represents a broader measure than the others. If employees, for example, were used to standardise stoppages data, it would tend to magnify the stoppage rates for countries (mainly less developed countries) that have relatively large 'informal' sectors and small 
formal sectors in which employees are formally identified. This can give an exaggerated impression of the impact of work stoppages on the economy as a whole. By standardising stoppages in terms of the labour force, we are effectively weighting the stoppage rate per (say) employee, by the proportion of employees in the labour force. $^{36}$

(b) Each country's contribution to the 'global' index is weighted according to its relative size amongst the 38 economies that make up the index. The relative size of each country is determined by each country's nominal US\$ GDP for each year. Table 4 column (ii) reports each country's average relative weight in the index. Note the dominance of the USA in the weighting arrangements, with its economy's weight averaging around $40 \%$ of the total, followed by Japan and Germany (with unified German data applied after 1992) averaging around $13 \%$ and $8 \%$ respectively. Clearly this 'global' index is very strongly affected by stoppages in the larger economies. Smaller economies with large populations and labour forces such as India and Nigeria are much less influential (Table 4 Column (iii)). This applies particularly to Nigeria, the most populous country in Africa, which experienced an explosive growth in stoppages during the mid-1990s. Because of the weighting arrangements, the impact of Nigeria's extraordinary level of stoppages on the 'global' index is minimal.

The rationale for the weighting arrangements is that we have sought to construct a global index of stoppages that reflects the influence of such stoppages on the world economy in general. Thus while Nigeria, for example, may have had an explosive increase in stoppages during the mid 1990s, the global economic impact of its experience has arguably been quite small. ${ }^{37}$ On the other hand, the explosive increase in stoppages in France during May and June of 1968 did register around the world, and arguable did influence perceptions and mind sets around much of the world. ${ }^{38}$

Finally note that the comparative GDP figures are not based on purchasing power parity adjusted estimates. The GDP estimates are all denominated in terms of nominal \$US values. These values, it is suggested, may better reflect commercial perceptions of the relative international economic status of the various economies that are constituents of the 'global' index. Table 4, column (vi) expresses the average relative size of the economies on a per capita basis.

(c) The stoppages data for the USA has been adjusted for the 1982 definitional change. Thus the total number of DNW is adjusted up for the estimate, made earlier in this paper, for DNW in small-scale stoppages. See Table 3.

(d) A number of approximations were employed. Because of earlier missing observations, instead of entering the global index in 1960, the following countries

\footnotetext{
${ }^{36}$ Let $S, E$ and $L$ be respectively stoppages, employees and the labour force. The stoppage rate per the labour force is $S / L=(E / L) \times(S / E)$ where $(E / L)$ is the proportion of employees in the labour force, i.e. the weight of employees in the labour force, and $(S / E)$ is the stoppage rate per employee.

${ }^{37}$ Moreover, stoppages in Nigeria have not been published to the world community via the ILO's Year Book of Labour Statistics for the last decade. This further reduces the measurement of influence of the Nigerian experience on the global economy.

38 A search on the internet will confirm the thousands of articles dealing with the May and June strikes in France during 1968. A similar search for Nigeria during the 1990s, on the other hand, proves to be much less fruitful. [Ed. Note: this may, however, simply reflect Eurocentricism of the media.]
} 
enter the global indexes in the following years: Peru 1965, South Korea 1964, Bangladesh 1971 (after it split from Pakistan), Spain 1963 and Iceland 1961. The following countries did not have observations for 2002, so the figure for 2001 was used as a proxy: France, Trinidad and Tobago, Guyana, and Bangladesh. Nigeria effectively had missing observations from 1999, with qualitative statements substituting for quantitative estimates of DNW. On the basis of limited quantitative commentary, the authors estimated DNW for Nigeria for the period 1999-2002. Intra-period missing data were linearly interpolated for: Malaysia 1963, The Philippines 1973-75 and Pakistan 1993. We appreciate that the use of these approximations is not an ideal way to construct a global index. However, we considered the arguments for and against the exclusion carefully, and came to a view that the approximations were, on balance, not unreasonable. Note also that the global index is dominated by the major OECD economies, all of which, with the exception of France, have no missing observations. Thus our adjustments for relatively small economies will likely make little difference to the overall index.

(e) The 'global' index excludes some notable major economies, in terms of population size. For example China, the Russian Federation, Brazil, Mexico and Indonesia are excluded. All of these omissions occur because of a lack of data. Data for China are unavailable; and data recently published by the ILO have been withdrawn. The Russian Federation has no data until 1990, Brazilian data from the ILO commences in 1985 and finishes in 1999 and Mexican data start in 1982. Indonesian data are not available from the ILO after 1997.

Figure 4 charts two 'global' indexes: global index \# 1 and global index \# 3. Global index \# 1 is the principal, and our preferred, index of global stoppages. Its construction is described in the previous paragraphs (items (a) to (e) above). Non-USA Global index \# 3 is the same of Global index \# 1, except of course it excludes entirely the USA. These two charts are included to illustrate that, in spite of the fact that the USA is the dominant economy in the global index, its absence from the index, does not destroy the overall shape of the 'global' index. The correlation coefficient for the two series is 0.92 .

Table 5 records 4 'global' indexes. Two of them, \# 1 and \# 3, appear in Figure 4, and have been discussed. Indexes \# 2 and \# 4 are the same as indexes \# 1 and \# 3 respectively, except the effect of the May-June 1968 French stoppages have been expunged. The French data have been expunged to allow an exploration of the data allowing for the possibility that the French experience is best treated as an outlier. We take an a priori view that the French data embodies important information that was influential globally; but we concede that it is a 'difficult' event to accommodate. ${ }^{39}$

Some features of the global index (\#1) are worth noting. First, the index spikes in 1968. This is entirely attributable to the broad-ranging wave of strikes in France during May and June. The strikes were triggered by student protests that soon spread to other parts of the economy. Had it not been for the upheaval of May and June during 1968, the global index would have recorded less than half of the stoppages that appear in Table 5. Secondly, the two later and lesser peaks in 'global' stoppages, occurring in 1970 and 1974, are attributable mainly to spikes in stoppages in those years in the USA. And thirdly, from the

\footnotetext{
39 Also, we recognize that if a larger number of economies were incorporated global index the relative importance of the French stoppages of May and June would be diminished.
} 
peak in stoppages during the late 1960s and early 1970s, the global index generally declined up until the 1990s, during which time stoppages numbers more or less stabilised. The average stoppage rates (for index \#1) for the 1960s, 1970s, 1980s and 1990s were respectively $287,319,137$ and 53 days not worked per thousand members of the labour force. These decade-average figures give a summary measure of the initial rise and subsequent decline in stoppages over the period.

Finally, it can be noted that broad trends in the global stoppages rate index appear to be loosely similar to, and perhaps related to, broad trends in at least 3 'global' macroeconomic variables: the unemployment rate, the inflation rate and the proportion of employees who are trade unionists (trade union density). Let us briefly discuss these, commencing firstly with the unemployment rate. The rise in global stoppages during the 1960s to a peak in the late 1960s (a major peak on 1968 and a lesser peak in 1970) corresponds broadly with a declining average OECD unemployment rate during the same period. The subsequent decline in global stoppages during the 1970s and beyond, corresponds to a rising average OECD unemployment rate during the same period, particularly during the 1980s. The second macroeconomic variable of interest is inflation. The average OECD inflation rate rose in a parallel fashion to global stoppages during the 1960s. However, the inflation rate peaked later than the global stoppages rate. Inflation peaked in 1974 and to a lesser extent in 1980, due in large measure to the essentially exogenous oil-price shocks of the time. The subsequent decline in global stoppages parallels the decline in inflation during the 1980s and beyond. Lastly, average OECD trade union density was generally trending upwards during the 1960s and 1970s. Stoppages were similarly trending upwards in 1960s, but not the 1970s. Thus while stoppages were falling during the 1970s, average OECD union density rose. During the 1980s both union density and stoppages declined. However while union density continued to decline during the 1990s and beyond, stoppages declined, if at all, only marginally. ${ }^{40}$

While these broad associations are suggestive, it is not the purpose of this paper to tease out statistically the links, if any, between global stoppages and these macroeconomic variables. This requires separate examination. Rather the purpose is to merely draw preliminary attention to these apparent relations, and point to them as an area of potential future research.

\section{Global Comparisons}

Table 6 gives a summary measure of association between our 4 global indexes and the 38 countries that make up the indexes. The correlation coefficients are reported alphabetically within broad geographic regions.

The degree of association between each individual country and the various global indexes is, on average, positive. Generally, countries from the Americas have the strongest association with the global indexes. This applies particularly to the USA and Canada. Also, it is important to note that they have a relatively strong association with the non-USA global indexes. This association will be explored in more detail in Section V of this paper.

\footnotetext{
${ }^{40}$ Note: Average OECD unemployment data (for 25 OECD economies) are referred to here because of the relative consistency and availability of these data. Average OECD inflation data are referred to here because the inclusion of certain non-OECD economies (e.g. Peru) that have experienced hyper-inflation at various times has the effect of seriously blowing out the 'average' global inflation rate series. Finally, trade union density data are based on union density rates for 13 OECD economies, for which these data are accessible.
} 
The correlation coefficients for Europe are also, on average, positive. Broadly speaking, the correlation coefficients tend to be higher for the larger economies: Italy, the UK, and to a lesser extent, France and Germany. For the smaller European economies, the correlations are considerably weaker.

The correlation coefficients for Asia and Oceania are typically positive. Relatively large coefficients are registered for Australia, Japan, Pakistan and Sri Lanka. Two notable exceptions are Israel and South Korea. In the case of South Korea, these results were affected by the major political changes that occurred in the late 1980s when political liberalisation freed up the capacity of unions to strike in support of their claims. There was an initial sharp rise in disputes followed by a subsequent decline in stoppages, pretty much in line with the global trend.

The African countries appear as a mixed bag. The relatively small, former British colony and Indian Ocean state of Mauritius has a positive association with the various global indexes. Likewise the North Western continental African country of Morocco, has a positive association with the various global indexes of work stoppages. Morocco has a relatively low per capita GDP level, a low union density rate (Table 4) and a high underand un-employment rate. South Africa and Nigeria have negative correlations with the global stoppage rates. In the case of South Africa, the wealthiest of Africa's sub-Saharan countries (notwithstanding its high under- and unemployment rate, see Table 4), work stoppages increased sharply during the late 1980 s, to peak in 1987. These stoppages ran parallel with political agitation for change to South Africa's apartheid policies current at the time. During the early 1990s, apartheid policies were dismantled and in 1994 South Africa's first multi-racial elections were held. Running parallel with the calming of political tensions, labour stoppages also drifted down during most of the 1990s. Thus while for the entire 1960-2002 period South African work stoppages appear to be negatively correlated with the global indexes, for the later post-apartheid period of 1990-2002, the negative association evaporates. Nigeria, on the other hand, had precious little political calm during the 1990s. Work stoppages exploded during the 1990s in parallel with the political turmoil visited upon the country during that period. These troubled times are discussed in more detail in Egwaikhide and Isumonah (2001).

\section{Mind the Gap}

As argued earlier in this paper, one of the most serious difficulties with the analysis of work stoppages on a global basis is the vast number of missing observations. The gaps in the records are much more serious than the problems of definitional and collection differences. There are basically two categories of countries with sizable numbers of missing observations. The first category includes countries with a reasonable or nearreasonable run of data. Those countries in this category, thirty three in number, are corralled into Table 7. Some of these countries have quite respectable collections. For example Hong Kong SAR (China) has data that stretches from 1966 to 2002 and the Russian Federation has a collection for 1990 to the present. Others are much more marginal. For example Brazil, the largest economy of South America, has at least three overlapping and ambiguous series published by the ILO for the period 1985 to 1999 .

The second category of countries with sizable numbers of missing observations includes countries that have so few accessible observations, that any assessment of their stoppages histories is not possible. These countries are excluded entirely from this study. 
Table 7 attempts to give a sense of the relative dimensions of stoppage rates in our collection of countries with missing observations. The first column compares each country's limited observations with the matched values of the main global index of stoppages, namely Global Index \# 1. The next four columns give the correlation coefficients for the matched values for each individual country with various global indexes. The final column gives the period of the observations.

The indexes are a mixed lot. Positive correlations tend to dominate for countries from Europe and America. Negative correlations tend to dominate for countries from Asia and Africa. However these results are quite tenuous and must be treated with caution. Let us focus on the larger of the economies, namely and in order of economic size: Brazil, Mexico, Russia, Taiwan (China), Turkey, Indonesia and Hong Kong SAR (China).

Brazil records relatively high dispute rates for the period 1985 to 1999 . The various partly overlapping stoppages series published by the ILO appear to differ markedly, which makes it difficult to evaluate events. However, on the basis of much of the available data, the overall dimensions of disputes in Brazil are far greater than those reflected in the Global indexes (see Table 7). During much of this period hyper-inflation plagued the economy. For the decade ended 1994, inflation averaged over $1000 \%$ per annum ${ }^{41}$. Inflation peaked in 1990 at over $2500 \%$ per annum and again in 1994 at over $2200 \%$ per annum. A new currency, the Real, was introduced in mid-1994 as a part of an anti-inflation strategy. Since 1997 inflation has been kept below 10\% per annum. While it may be the case these relatively high inflation rates may explain some of Brazil's relatively high stoppage rates, some caution would need to be exercised in attributing high stoppage rates to hyperinflation. This is because hyper-inflation tends to lead to a breakdown of commercial life, and whether the inflation rate is $1000 \%$ per annum or $2000 \%$ per annum, is not likely to make much difference to commercial transactions. Either way, cash-based transactions, wage payments and normal contractual arrangements become unsustainable.

Mexican stoppages data is available from the ILO from 1982. These data are charted in Figure 6. Although the correlation coefficients with the global indexes are small, the Mexican series and the global series appear to be quite similar after the mini peak in recorded stoppages in Mexico in 1987. The Mexican inflation rate also peaked at 140\% per annum during the same year (World Bank World Tables). The decline in Mexican stoppages is quite marked over the last 7 years or so of the period under review.

Russian stoppages data are available from the ILO for the period 1990-2001. These data are charted in Figure 5 and are broadly comparable to the global index readings for the same period, at least in terms of the size of the disputes, notwithstanding the negative sign of the correlation coefficients.

Stoppages data for Taiwan (China) barely register in Figure 5. For the years for which data are available, ${ }^{42}$ the ratio of global stoppages to these stoppages averaged 108 to 1.

Turkish stoppages data are available from the ILO for the period 1963-2001 excluding the years 1981-83. During this period the military took control of the country. Civilian government more or less returned at the end of 1983. Prior to the military takeover in September 1980, work stoppages in Turkey were at historically high levels, as indicated in Figure 6. However, it is notable that, although the stoppage rate during 1977-80 was much greater than the pre-1977 rate, the 1977-80 rate was broadly comparable to the global

\footnotetext{
${ }^{41}$ All data from World Bank World Tables.

${ }^{42}$ Taiwan (China) publishes data on the number of stoppages and the number of workers involved, but often does not publish on days not worked due to stoppages.
} 
stoppage rate. Since the return to civilian rule in 1983 stoppage rates in Turkey have been broadly comparable to the global index readings for the same period, in terms at least of the of the size of the disputes.

Indonesian stoppages data are available from the ILO for the period 1960-1997. During 1997 the 'Asian Financial Crisis' struck a number of East Asian economies including Indonesia. The political effect of the crisis was the demise of the Suharto government, which had been in power effectively since 1966. Post-Suharto administrations have seemingly been unable to communicate stoppages data to the ILO. In any case, Indonesian stoppages have been historically a small proportion of global rates. Over the period 196097, the ratio of global stoppages to Indonesian stoppages averaged 16 to 1 .

Hong Kong SAR (China) stoppages data are available for 1966-2002. These data are on average about 3 per cent of the average size of global stoppages. These data are relatively strongly correlated with the global indexes, as indicated in Table 7.

A notable feature of this review of global stoppage rates is that East Asian economies typically have markedly lower stoppage rate statistics than countries from other regions. These differences are summarised in Table 8. While some caution needs to be exercised when making these comparisons, given the different periods involved, it is clear that East Asian rates are substantially lower than global stoppage rates.

\section{Interdependence in Global Stoppages}

Many commentators have pointed to similarities in the patterns of change in work stoppage rates internationally, but particularly amongst OECD countries (see for example Shalev 1992, Edwards and Hyman, 1994, Aligisakis, 1997, Diduch, 1998, Perry and Wilson, 2001, 2003 and Healy, 2002). In this section we explore further the issue of interdependence in global stoppages from a 'super-macro' point of view. This is effected by dividing the world into two approximate 'halves', and then looking at the relationship between these two 'halves'.

We make two splits of the world for testing purposes. The first split is the USA versus the Rest of the (non-USA) World. The second split is North America (USA plus Canada) versus the Rest of the (non-North American) World. The rationale for the first split is as follows. The USA is the world's largest economy and, over the last 40 years, the USA has accounted for about $40 \%$ of the global economic activity of the 38 countries that make up Table 4 . The other 37 countries, of course, account for about $60 \%$ of global economic activity as defined in Table 4. Thus a USA versus the Rest of the World data split comes pretty close to being a 'half and half' split. In addition, it can be argued that the USA has been a singularly important separate influence in the world's political economy, and indeed has come to be the world's single remaining 'superpower', at least for the time being.

The second split combines Canada and the USA, i.e. North America, and splits it from the Rest of the World. The rationale for the second split is that the USA and Canada have much in common (including the North American Free Trade Agreement, since 1994) ${ }^{43}$ and combining the two recognises the many commonalities that exist in the two countries.

The issue we seek to address here is the extent to which changes in one 'half' of the world are influenced by, and influence, the other 'half' of the world.

43 This Agreement includes Mexico as well. 
We commence this analysis by firstly looking at some selected statistical properties (stationarity properties) of the various 'global' stoppages indexes employed in this exercise. Then secondly, we look at the statistical evidence for the presence or otherwise of interdependence between various series constructed.

\section{Stationarity Tests of the Global Indexes}

In order to determine the long-term relationship between variables, stationarity tests must be conducted. Table 9 presents the results of Augmented Dickey Fuller (ADF) tests on the various indexes under review. The Indexes are as follows:

1. The USA Stoppage Rate (USA)

2. The Non-USA Global Stoppage Rate (NonUSA)

3. The Non-USA Global Stoppage Rate adjusted for France 1968 (NonUSAEX)

4. The North American Global Stoppage Rate (NAM)

5. The Non-North American Global Stoppage Rate (NoNAM)

6. The Non-North American Global Stoppage Rate adjusted for France 1968 (NoNAM)

The terms above in brackets are the abbreviations for the variables used in the tables. The expression 'adjusted for France 1968' refers to the exclusion of the effect of the previously-discussed May-June 1968 stoppages in France, as these might best be treated as an outlier.

The results of the ADF tests are given in Table 9. The results indicate that all of the 6 'semi-global' series are stationary when first differenced in natural logs. However, it has been argued that these tests may not be adequate if there is evidence of a break in the series. Such a break might be brought about by, say, an unusually large increase in strikes during a particular year or some other extended timeframe. To test for this we employ a test developed by Zivot and Andrews (1992). They developed an objective procedure that sequentially tests for unit roots in the presence of potential, but unknown, breaks in data series. The Zivot and Andrews (ZA) terminology followed that of Perron (1989) and allowed tests for three possible situations: clear break in trend (crash); break in trend slope; and both conditions. The models were simply called A, B and C. Appendix A gives a more detailed explanation of these models.

The results of the ZA tests are given in Table 10. These tests confirm that the series are stationary in first-differences of logged values. They also suggest the possible presence of structural breaks for all the series. For example, consider the USA stoppages index for which a model A (clear break) is tested. The test statistic (-7.79 in Table 10) is significant at the 5\% level, and is suggestive of a clear break in the series around 1985, which appears in brackets below the test statistics. 


\section{Cointegration Tests}

Our next step is to test for interdependence between the various country groupings. To test for the presence of a statistically significant long-term relationship between the country groupings, we test to see if the various paired 'semi-global' groupings are cointegrated, employing the Johansen (1991) Rank Tests. The results of these tests are given in Table 11. The bottom line is that the tests are supportive (at the conventional 5\% level of significance) of the presence of a long-term cointegrated relation for (i) the USA and the Rest of the World adjusted for the 1968 French Strikes (NonUSAEX), and (ii) North America (NAM) and the Rest of the World (NAMEX). These results are rather mixed. They are not unequivocally supportive of a view that the inclusion of the 1968 French data generates a cointegrated result. Nor are they unequivocally supportive of a view that a data split along the lines of the USA versus the non-USA generates a cointegrated relation.

We next test for evidence of cointegration in the presence of possible trend breaks in the cointegrated relation between the variables. The results of the Johansen tests in Table 11 do not necessarily allow for the possibility of a trend break in the long-term relation. To address this, we employ a technique developed by Inoue (1999), who (among others) showed that if one or more series contain a break in trend, this may yield misleading results as to the rank of the cointegration system (and indeed whether there is cointegration at all). As was the case with Zivot and Andrews (1992), the procedure developed by Inoue (1999) determines any break endogenously for a test of cointegrating rank within the presence of a possible (but unknown) trend-break. While other procedures are available (cf. Gregory and Hansen, 1996), a significant advantage for present purposes is that the Inoue test is a Johansen (1991) type test and therefore does not require prior specification of the structure of a cointegrating equation. The Inoue (1999) approach therefore allows direct comparison with the Johansen (1991) outcomes. Appendix B gives a more detailed explanation of the Inoue (1999) approach.

The results of the Inoue tests are given in Table 12. Here we find that, when allowance is made for a possible trend break in the cointegrated relation between the various pairs of variables, the results of the Johansen tests are partly contradicted. The Inoue test results are consistent with a view that (i) there was a long-run cointegrated relation between USA stoppages and the Rest of the World's stoppages (NonUSA), and (ii) there was a long-run cointegrated relation between North American stoppages (NAM) and the Rest of the World's stoppages (NoNAM). These results are supported at the $1 \%$ or $5 \%$ levels of significance, depending upon which model of structural break is applied. However, it is important to emphasise that these results apply on the assumption that there is a structural break in the long-term cointegrated relation, on or around the date indicated in Table 12 (which in turn depends upon the particular model (A, B or C) of structural break favoured). The Johansen tests (Table 11) are ambiguous as to the effect of including the 1968 French strikes on the presence of a cointegrated relation between various semi-global stoppages indexes. The Inoue tests, on the other hand, tend to support the view that the various semiglobal paired series are most strongly cointegrated when the series include the effects of the French May-June 1968 stoppages. The Inoue-test results are consistent with a view that the major upheaval in France in 1968 had a long-term influence on USA stoppages - albeit with allowance being made for a possible trend break in the cointegrated relation between the various pairs of variables ${ }^{44}$.

\footnotetext{
${ }^{44}$ Note that this does not mean that model B, with its trend break occurring around 1967, is to be necessarily favoured. Rather, the point to note is that when the data in the Rest of the World series incorporate the 1968-French stoppages, the series are cointegrated with the USA series, provided allowance is made for a break point of some form or other.
} 
Let us consider the first row of results of Table 12 a little more closely, so as to explain matters further. This top row of results in the table tests for cointegration with breaks for the USA and the Rest of the (non-USA) World ${ }^{45}$. If a structural break of the form covered in models A or C is assumed, then a structural break is in evidence around 1980-1981 ${ }^{46}$. If a structural break of the form covered in model B is assumed, then a structural break is in evidence around 1967. Both of these dates represent periods when certain major developments occurred in the industrial relations environment in either the USA or the Rest of the (Non-USA) World. For example, in 1981 USA President Ronald Reagan fired over 11,000 air-traffic controllers for refusing to return to work. It has been suggested that this act set the tone of the Reagan Administration's tough approach towards recalcitrant unions in the $\mathrm{USA}^{47}$. Likewise the possible break point of 1967 corresponds approximately with the aforementioned French student uprising during May-June of 1968. This event arguably informed and influenced the global industrial relations scene for some time ${ }^{48}$.

In sum, there appears to be quite firm evidence of interdependence in stoppage rates at a global level. Our results are consistent with a view that major changes in one 'half' of the world are observed, sometimes copied, but always noted, by the other 'half' of the world.

\section{Concluding Comments}

In this paper international trends in work stoppages have been explored. It has been observed that there are notable differences in the collecting and compiling practices used by countries around the world. It is argued that the effect of these differences on limiting the comparability of data between countries can be minimised by focussing on days not worked (DNW), rather than, say, the number of stoppages or number of workers involved in stoppages. This is simply because DNW data tend to be dominated by large stoppages. Thus either the decision not to count small-scale stoppages or the failure to accurately count the number of small-scale stoppages, will have a limited impact on the total tally of stoppages.

The make up of USA days not worked data tends to confirm the above. Here we note that major stoppages dominate the aggregate series during the period 1947 to 1981 . However, the decision in the USA to exclude from its tally of stoppages all disputes involving less than 1000 workers, does seriously affect the aggregate stoppages tally. In addition, this threshold puts the USA at odds with all other countries in Table 1. The largest threshold limit for any other country in Table 1 is much less than the USA threshold. The USA threshold has the effect of excluding more than $90 \%$ of all stoppages (based on the 194781 data). Thus a rich source of information on small-scale stoppages is lost. The 1000person threshold does not have as dramatic an effect on the overall number of DNW or the general shape of the aggregate series, at least not for the period 1947-81. In the light of the criticisms raised against the post-1981 stoppages definition, we have attempted to gross-up

\footnotetext{
${ }^{45}$ Recall that the Rest of the (Non-USA) World in this paper is composed of 37 of the 38 countries that appear in Tables 1 and 4.

${ }^{46}$ Note that the timing of the trend-break should not necessarily be assumed to be precisely on the date of the year nominated. Rather, the break is likely to occur around the time of the year nominated, give or take maybe a year or two.

${ }^{47}$ See for example: http://www.cnn.com/SPECIALS/2001/reagan.years/whitehouse/airtraffic.html

${ }^{48}$ It is important to point out that the above interpretations of the events associated with the identified break points 1980-81 and 1967 are no more than an after-the-fact judgement about the importance of certain historical episodes. The statistical techniques are themselves silent on the significance of one event over another.
} 
the aggregate data with forecast figures of small-scale stoppages. While this procedure is necessarily limited in its scope and accuracy, we argue that these estimates give a reasonable idea of how the data might have looked had there not been the definitional change. It is preferable to adjust the data in one way or another so as to facilitate comparisons over time and comparisons with other countries.

As problematic as the different approaches to collecting data on stoppages are, we argue the more serious problem is the large number of missing observations. This applies particularly to less developed countries, but it also applies to other major economies. It is recognised that for many poorer countries plagued by problems of war and/or pestilence, the collection of work stoppages data may not be a high priority. But for middle-ranking countries, it seems curious that sufficient resources cannot be mustered to gather these data. We recommend that, if financial difficulties limit the preparedness of countries to collect these data, they limit their collections to larger stoppages (say, stoppages involving 100 workers or more) so as to at least provide policy makers and future generations with some indication of how these important industrial relations statistics have changed over the years.

Notwithstanding the difficulties involved in making international comparisons, we develop a preliminary global stoppages index, where the basic measure is the weighted global number of DNW due to work stoppages. The 38 countries that make up the index are weighted according to their relative nominal US\$ values of GDP. This index is used for comparison purposes with the 38 individual countries that make up the global index, as well as 34 other countries that have missing observations.

We find that the stoppage rate series for most individual countries that make up the global stoppage rate index are positively correlated with the global index. This applies particularly to the largest (10) economies that make up the global index.

Finally we test the global data for evidence of interdependence. We split the world into two, and see if stoppages in one half reveals evidence of interdependence with stoppages in the other half. The two halves are essentially (i) the USA and (ii) the rest of the world. Using Inoue's cointegration tests in the presence of possible trend-breaks in the relation between the variables, we find strong evidence of cointegration. This evidence is consistent with a view that stoppage rates around the globe are potentially influential beyond the bounds of their own borders. Future research may reveal if there are any general or global influences that might account for the ebb and flow of global stoppages 


\section{References}

Aligisakis, M. (1997), 'Labour Disputes in Western Europe: Typology and Tendencies', International Labour Review, Vol. 136, No. 1 (Spring), pp. 73-94.

Ashenfelter, O., and Johnson, G. E. (1969), 'Bargaining Theory, Trade Unions, and Industrial Strike Activity', American Economic Review, Vol. 59, March, pp. 35-49.

Australian Bureau of Statistics [ABS] (2001), Labour Statistics Concepts, Sources and Methods 2001, ABS Catalogue No. 6102.0, Commonwealth of Australia.

Booth, A. (1985), 'The Free Rider Problem and a Social Custom Model of Trade Union Membership', Quarterly Journal of Economics, 100, February, pp. 253-61.

Diduch, A. M. (1998), 'Global Strike Patterns, Macroeconomic Variables and Industrial Relations', International Review of Comparative Public Policy, Vol. 10, pp. 3-34.

Dutt, R. (2000), 'Disturbing Trends in Strikes, Lockouts and Closures' Labour File: A Monthly Journal Of Labour And Economic Affairs, http://www.labourfile.org/cec1/labourfile/lf_2000/Article2.htm

Ebbinghaus, B. and Visser, J. (2000), The Societies of Europe: Trade Unions in Western Europe since 1945, Macmillan Reference, London.

Edwards, P. K. and Hyman, R., (1994) in Hyman, R. and Ferner, A. (eds), Strikes and Industrial Conflict: Peace in Europe? Oxford, Blackwell, pp. 250-80.

Egwaikhide, F. O. and V. A. Isumonah (2001), 'Nigeria Paralysed: Socio-political Life Under General Sani Abacha', African Development, Vol. XXVI, Nos. 3\&4, pp. 219-241.

Engle, R.F. and Granger, C.W.J. (1987), 'Co-integration and Error Correction: Representation, Estimation and Testing’, Econometrica, Vol. 55, No.2.

Fisher, M. (1973), Measurement of Labour Disputes and their Economic Effects, OECD, Paris.

Freeman, R. B. and Medoff, J. L. (1984), What Do Unions Do?’ Basic Books, New York.

Gordon, A. (1988), The Evolution of Labour Relations in Japan Heavy Industry 1853-1955, Harvard University Press, Cambridge, Massachusetts.

Gregory, A. W. and Hansen, B. E. (1996a), 'Residual Based Tests for Cointegration in Models with Regime Shifts', Journal of Econometrics, Vol. 70, No. 1, pp. 99-126.

Gregory, A. W. and Hansen, B. E. (1996b), 'Practitioners Corner: Tests for Cointegration in Models with Regime Shifts', Oxford Bulletin of Economics and Statistics, Vol. 56, No. 3, pp. 555-560.

Griffin, J. (1939), Strikes: A Study in Quantitative Economics, Columbia University Press, New York.

Hansen, A. (1921), 'Cycles and Strikes', American Economic Review, Vol. 11, pp. 616-21.

Healy, J. (2002), 'Peace at Last: Recent Trends in Australia's Industrial Action', The Australian Bulletin of Labour, Vol. 28, No. 2, June, pp. 80-87. 
Hendry D. F. and Krolzig, H-M (2001), Automatic Econometric Model Selection Using PcGets, TCL.

Hirsch, B. T. (2003), 'Union Membership and Coverage Database from the Current Population Survey: Note', Industrial and Labour Relations Review, Vol. 56, No. 2, January pp. 349-54.

Inoue, A. (1999), 'Tests of Cointegrating Rank with a Trend-break', Journal of Econometrics, Vol. 90, pp. 215-237.

International Labour Office (1923), Studies and Reports, Series N (Statistics) No. 4, International Conference of Labour Statisticians 1923, Introduction.

International Labour Office (ILO), Yearbook of Labour Statistics, Geneva, various issues plus ILO website: http://laborsta.ilo.org/.

International Labour Office, (1993), Sources and Methods: Labour Statistics, Vol. 7: Strikes and Lockouts, Geneva.

International Labour Office, (1993), Fifteenth International Conference of Labour Statisticians, Geneva.

International Labour Office, (1999), Sources and Methods: Labour Statistics, Vol. 9: Transition Countries, Geneva.

International Labour Office, (2004), Sources and Methods: Labour Statistics, Vol. 7: Strikes and Lockouts, as displayed at: http://laborsta.ilo.org/.

Jackson, M. P. (1987), Strikes: Industrial Conflict in Britain, the USA, and Australia, New York, St Martins Press.

Johansen, S (1991), 'Estimation and Hypothesis Testing of Cointegration Vectors in Gaussian Vector Autoregressive Models', Econometrica, Vol.59, pp. 1551-1580.

Kaufman B. E. (1981), 'Bargaining Theory, Inflation, and Cyclical Strike Activity in Manufacturing', Industrial and Labor Relations Review, Vol. 34, April, pp. 333-55.

Kaufman B. E. (1982), 'The Determinants of Strikes in the United States, 1900-1977', Industrial and Labor Relations Review, Vol. 35, No. 4, pp. 473-90.

Kelly, J. and C. Nicholson (1980), 'Strikes and Other Forms of Industrial Action', Industrial Relations Journal, Vol. 11, No. 5, pp. 20-31.

Kennedy, T. (1980), European Labor Relations, D.C. Heath, Lexington.

Knowles, K. (1952), Strikes: A Study of Industrial Conflict, Basil Blackwell.

Korpi, W.(1981), 'Unofficial Strikes in Sweden', British Journal of Industrial Relations, Vol. 19, No. 1, pp. 66-86.

MacKinnon, James G., Alfred A. Haug and Leo Michelis, (1999), 'Numerical Distribution Functions Of Likelihood Ratio Tests For Cointegration,' Journal of Applied Econometrics, Vol.14, No. 5, Sep/Oct, pp. 563-577.

McCammon, H. J. (1993), 'From Repressive Intervention to Integrative Prevention: The US State's Legal Management of Labor Militancy, 1881-1978', Social Forces, Vol. 71, No. 3, pp. 569-601. 
McGuire, J. W. (1996), 'Strikes in Argentina: Data Sources and Recent Trends,' Latin American Research Review, Vol. 31, No. 3, pp. 127-150.

Mitchell, B. R. (2003a), International Historical Statistics: Africa, Asia and Oceania $1750-2000,4^{\text {th }}$ Ed., New York, Palgrave Macmillan.

Mitchell, B. R. (2003b), International Historical Statistics: Europe, 1750-2000, $4^{\text {th }}$ Ed., New York, Palgrave Macmillan.

Mitchell, B. R. (2003c), International Historical Statistics: The Americas and Australasia, 1750-2000, $4^{\text {th }}$ Ed., New York, Palgrave Macmillan.

Monger, J. (2004), 'International Comparisons of Labour Disputes in 2002', Labour Market Trends, April, Vol. 112, No. 4, pp. 145-152.

Morris, A. and Wilson, K., (1999), 'Strikes and the Accord: A Final Word,' Australian Bulletin of Labour, Vol. 25, pp. 63-71.

Morris, T. (2003), 'Unionization Matters: An Analysis of Post-World War II Strikes', Sociological Enquiry, Vol. 73, No. 2, May, pp. 245-64.

Mumford, K. (1993), 'A Critical Comparison of Models of Strike Activity', Oxford Bulletin of Economics and Statistics, Vol. 55, August, pp. 285-304.

Naylor, R. (1989), Strikes, Free Riders and Social Custom', Quarterly Journal of Economics, 104, November, pp. 771-85.

Oguejiofor, G. C. (2004), 'Gas Flaring in Nigeria: Some Aspects for Accelerated Development of Sasolchevron Gtl Plant at Escravos,' $7^{\text {th }}$ Africa-USA International Conference on Manufacturing Technology (MANUTECH 2004).

Oxnam, D. W. (1975), 'The Incidence of Strikes in Australia' in J. E. Isaacs and J. W. Ford (eds.), Australian Industrial Relations: Readings, $2^{\text {nd }}$ Edition, Sun Books, Melbourne.

Perron, Pierre (1989), 'The Great Crash, The Oil Price Shock, and the Unit Root Hypothesis,' Econometrica, Vol. 57, No.6.

Perry, L. J. (1980), Trade Unions and Inflation, CAER Paper No 9, March, Centre for Applied Economic Research, University of New South Wales.

Perry, L. J. and Wilson, Patrick J. (2001), 'The Accord and Strikes: An International Perspective', Australian Journal of Labour Economics, Issue 4, 2000-2001.

Perry, L. J. and Wilson, Patrick J. (2003), 'An Analysis of International linkages in Strike Activity’, International Journal of Employment Studies, Vol. 11, No. 2, October, pp. 47-74.

Rees, A. (1952), 'Industrial Conflict and Business Fluctuations', Journal of Political Economy, Vol. 60, No. 5, pp. 371-82.

Shalev, M. (1992), 'The Resurgence of Labour Quiescence', in M. Regini, ed. (1992) The Future of Labour Movements, Sage Publications.

Snyder, D. (1977), 'Early North American Strikes: A Reinterpretation', Industrial and Labor Relations Review, Vol. 30, No. 3, pp. 325-41. 
Sweet, T. G. and D. Jackson (1977), 'The Classification and Interpretation of Strike Statistics: An International Comparative Analysis', The University of Aston Management Centre Working Paper Series, No. 97, May.

Taylor, B., Kai, C. and Qi, L. (2003), Industrial Relations in China, Edward Elgar, Cheltenham, UK.

Tracy, J. S. (1986), 'An Investigation into the Determinants of US Strike Activity', American Economic Review, Vol. 76, pp. 423-36.

Turner, H. A. (1969), Is Britain Really Strike Prone? A Review of the Incidence, Character and Costs of Industrial Conflict, Occasional Paper No. 20, University of Cambridge, Department of Economics, Cambridge University Press, Cambridge.

Wallace, M., Rubin, B. A., and Smith, B. T. (1988), 'American Labor Law: Its Impact on Working Class Militancy, 1901-1980’, Social Science History, Vol. 12, No. 1, pp. 1-29.

Walsh, K. (1983), Strikes in Europe and the United States: Measurement and Incidence, Frances Pinter, London.

Yoder, D. (1940), 'Economic change and Industrial Unrest in the USA', Journal of Political Economy, Vol. XLVIII, pp. 222-37.

Zivot, E. and Andrews, D.W.K. (1992), 'Further Evidence on the Great Crash, the OilPrice Shock, and the Unit Root Hypothesis', Journal of Business and Economic Statistics, Vol. 10, No.3. 


\section{Tables}


Table 1: International Work Stoppage Statistics: Comparisons of Definitional and Collecting Methodologies

\begin{tabular}{|c|c|c|c|c|c|c|c|}
\hline Country & Minimum criteria & $\begin{array}{c}\text { Are lockouts } \\
\text { counted } \\
\text { separately? }\end{array}$ & $\begin{array}{c}\text { Are political } \\
\text { strikes } \\
\text { included? }\end{array}$ & $\begin{array}{c}\text { Are } \\
\text { indirectly } \\
\text { affected } \\
\text { workers } \\
\text { included? }\end{array}$ & $\begin{array}{l}\text { Minimum } \\
\text { collection } \\
\text { frequency } \\
\text { published }\end{array}$ & $\begin{array}{l}\text { Are parties } \\
\text { legally } \\
\text { obliged to } \\
\text { report? }\end{array}$ & Primary data source \\
\hline Australia & 10 workdays & no & yes & yes & monthly & no & employers, media, union publications \\
\hline \begin{tabular}{|l|l} 
Austria \\
\end{tabular} & none & no & yes & no & annual & no & unions \\
\hline Bangladesh & none & no & yes & yes & monthly & yes & employers and workers \\
\hline Canada & half day/10 persons & yes & yes & yes & monthly & no & government ministries, employers media \\
\hline Cyprus & 0.75 of a day & no & no & yes & monthly & yes/no & media, employers, unions, ministries \\
\hline Denmark & 100 workdays & no & yes & yes & annual & no & employers federation \\
\hline Finland & 1 hour & yes & yes & yes & monthly & no & employers and media \\
\hline France & 1 day & no & yes & yes & monthly & no & government inspectors \\
\hline Germany & 10 workers $/ 100$ workdays & yes & yes & no & quarterly & yes & employer \\
\hline Guyana & n.a. & n.a. & n.a. & n.a. & n.a. & n.a. & n.a. \\
\hline Iceland & Unspecified restrictions & n.a. & n.a. & no & n.a. & n.a. & n.a. \\
\hline India & 10 workers & yes & no & yes & monthly & no & employers, employees, police records \\
\hline Ireland & 1 days duration/10 workdays & no & yes & yes & quarterly & no & direct enquiry, media \\
\hline Israel & 10 days/2 hours duration & yes & no & no & annual & yes & employer, media \\
\hline Italy & none & no & yes & no & monthly & yes & police \\
\hline Japan & none & yes & yes & no & monthly & yes & employers, unions \\
\hline Korea & none & yes & no & no & annual & yes & employers, unions \\
\hline Malaysia & 1 day duration & no & yes & yes & annual & yes & unions \\
\hline Mauritius & 30 minutes & yes & yes & no & annual & no & management, workers, unions, police, media \\
\hline Morocco & n.a. & n.a. & n.a. & n.a. & n.a. & n.a. & n.a. \\
\hline Netherlands & none & no & yes & yes & monthly & no & media, employers, employees \\
\hline New Zealand & 10 workdays & yes & yes & yes & monthly & yes/no & employers \\
\hline Nigeria & none & no & yes & no & quarterly & yes & employers, unions, media \\
\hline Norway & 1 day duration & no & yes & no & annual & no & n.a. \\
\hline Pakistan & none & no & no & yes & monthly & yes & employers \\
\hline Peru & none & no & yes & yes & annual & yes & unions, employers \\
\hline Philippines & 1 workday or shift & no & no & yes & weekly & no & labour, management \\
\hline Puerto Rico (USA) & none & no & no & yes & quarterly? & yes & unions, police \\
\hline Singapore & none & no & no & no & annual & no & employers, unions, government \\
\hline South Africa & 2 workers & no & yes/no & no & annual & yes & employers \\
\hline Spain & 1 hour duration & n.a. & yes & no & monthly & n.a. & employers, unions, \\
\hline Sri Lanka & 50 workdays & excludes lockouts & no & no & monthly & no & media \\
\hline Sweden & 8 workhours & yes & yes & no & annual & no & media \\
\hline Switzerland & 24 hours duration & no & yes & yes & annual & no & media, employers, unions \\
\hline Thailand & none & yes & no & no & monthly & no & unions, workers \\
\hline Trinidad \&Tobago & none & no & no & no & annual & yes/no & direct enquiries \\
\hline UK & 10 workers $/ 100$ workdays & no & no & yes & monthly & no & employers, employees, media \\
\hline USA & 1000 workers & no & no & yes & monthly & no & media, employers, unions \\
\hline
\end{tabular}

Sources: International Labour Office (ILO) Sources and Methods: Labour Statistics, available at http://laborsta.llo.org/. Monger (2004). n.a. not available. 
Table 2: Explaining Small-Scale USA Work Stoppages

\begin{tabular}{lcccc}
\hline Explanatory Variables & Coefficient Estimate & Standard Errors & 't' Statistics & 't' Statistics Probability \\
\hline$\Delta \ln S B$ & 0.155 & 0.034 & 4.54 & 0.000 \\
$\Delta \ln D_{-2}$ & -1.612 & 0.518 & -3.11 & 0.006 \\
$\Delta U_{-2}$ & -0.070 & 0.022 & -3.16 & 0.005 \\
$\Delta U_{-3}$ & 0.057 & 0.021 & 2.67 & 0.015 \\
$\Delta \ln P$ & 0.045 & 0.012 & 3.88 & 0.001 \\
$\Delta \ln P_{-1}$ & -0.064 & 0.016 & -3.95 & 0.001 \\
$\Delta \ln P_{-2}$ & 0.033 & 0.014 & 2.31 & 0.032 \\
$\Delta \ln P_{-3}$ & -0.026 & 0.010 & -2.67 & 0.015 \\
$\Delta \ln Q$ & 0.022 & 0.009 & 2.40 & 0.026
\end{tabular}

$\mathrm{R}^{2}=0.80 \quad \mathrm{R}^{2}$ (Adj.) $=0.72$

Sources: US Department of Labor, Bureau of Labor Statistics (BLS), Monthly Labor Review, various issues, BLS, Employment and Earnings, various issues, Hirsch (2003), Statistical Abstract of the United States, U.S. Dept. of Commerce, Bureau of the Census, Historical Statistics of the United States: Colonial Times to 1970 
Table 3: USA Days not worked Due to Stoppages (thousands of days)

\begin{tabular}{|c|c|c|c|}
\hline Year & $\begin{array}{l}\text { Theoretical Small-Scale } \\
\text { Stoppages }\end{array}$ & Actual Large-Scale Stoppages & Theoretical Total of Stoppages \\
\hline 1982 & 4999 & 9061 & 14060 \\
\hline 1983 & 4669 & 17461 & 22130 \\
\hline 1984 & 4001 & 8499 & 12500 \\
\hline 1985 & 3571 & 7079 & 10650 \\
\hline 1986 & 4245 & 11861 & 16106 \\
\hline 1987 & 4086 & 4469 & 8554 \\
\hline 1988 & 4081 & 4381 & 8462 \\
\hline 1989 & 5635 & 16530 & 22165 \\
\hline 1990 & 4860 & 5926 & 10786 \\
\hline 1991 & 4076 & 4584 & 8660 \\
\hline 1992 & 3786 & 3989 & 7774 \\
\hline 1993 & 3331 & 3981 & 7312 \\
\hline 1994 & 3265 & 5022 & 8287 \\
\hline 1995 & 3303 & 5771 & 9074 \\
\hline 1996 & 3297 & 4889 & 8185 \\
\hline 1997 & 3493 & 4497 & 7990 \\
\hline 1998 & 3668 & 5116 & 8784 \\
\hline 1999 & 3607 & 1996 & 5602 \\
\hline 2000 & 5527 & 20419 & 25946 \\
\hline 2001 & 3248 & 1151 & 4399 \\
\hline 2002 & 2982 & 660 & 3642 \\
\hline
\end{tabular}


Table 4: Index-Constituent Countries: Selected Comparative Data (ranked by strike rate)

\begin{tabular}{|c|c|c|c|c|c|c|c|c|}
\hline & $\begin{array}{c}\text { Stoppage } \\
\text { Rate } \\
\text { Average } \\
1960-2002\end{array}$ & $\begin{array}{c}\text { GDP } \\
\text { Weighted } \\
\text { Average } \\
1960-2002\end{array}$ & \begin{tabular}{|c|} 
Labour \\
Force \\
Weighted \\
Average \\
$1960-2002$
\end{tabular} & $\begin{array}{c}\text { Inflation } \\
\text { Average } \\
\text { Annual } \\
\text { 1961-2002 } \\
(\%)\end{array}$ & $\begin{array}{c}\text { Real GDP } \\
\text { Growth } \\
\text { Average } \\
\text { Annual } \\
1961-2002 \\
(\%) \\
\end{array}$ & $\begin{array}{c}\text { Per Capita } \\
\text { (US\$) GDP } \\
\text { Relative to } \\
\text { USA 2002 } \\
(\%) \\
\end{array}$ & $\begin{array}{c}\text { Union } \\
\text { Density } \\
1994-95 \% \\
\text { of Labour } \\
\text { Force }\end{array}$ & $\begin{array}{c}\text { Unemploy } \\
\text { ment Rate } \\
2002 \\
(\%)\end{array}$ \\
\hline & (i) & (ii) & (iii) & (iv) & $(\mathrm{v})$ & (vi) & (vii) & (viii) \\
\hline Switzerland & 2 & 1.12 & 0.4 & 3.5 & 2.2 & 146 & 20 & 3.1 \\
\hline Thailand & 5 & 0.41 & 2.9 & 4.5 & 6.8 & 9 & 3 & 2.4 \\
\hline Bangladesh & 7 & 0.15 & 5.1 & 9.4 & 3.7 & 1 & N.A. & 40.0 \\
\hline Austria & 11 & 0.80 & 0.4 & 3.8 & 3.2 & 107 & 37 & 5.3 \\
\hline Pakistan & 15 & 0.40 & 4.6 & 7.8 & 5.4 & 2 & 6 & 7.8 \\
\hline Netherlands & 19 & 1.63 & 0.7 & 4.3 & 3.2 & 98 & 22 & 2.3 \\
\hline Germany & 20 & 8.35 & 3.6 & 3.3 & 2.7 & 103 & 30 & 8.1 \\
\hline Malaysia & 20 & 0.27 & 0.7 & 3.0 & 6.7 & 15 & 12 & 3.8 \\
\hline Japan & 40 & 13.50 & 6.8 & 3.6 & 4.9 & 141 & 19 & 5.4 \\
\hline Morocco & 47 & 0.17 & 0.9 & 4.9 & 4.2 & 5 & 5 & 19.0 \\
\hline Philippines & 47 & 0.35 & 2.3 & 10.4 & 3.9 & 4 & 23 & 10.2 \\
\hline Korea (South) & 52 & 0.92 & 1.8 & 12.4 & 7.5 & 45 & 9 & 3.1 \\
\hline South Africa & 53 & 0.70 & 1.3 & 10.2 & 3.2 & 13 & 22 & 29.9 \\
\hline Singapore & 53 & 0.18 & 0.1 & 2.8 & 8.1 & 85 & 14 & 1.8 \\
\hline Sweden & 61 & 1.35 & 0.5 & 5.7 & 2.6 & 106 & 77 & 4.0 \\
\hline Norway & 64 & 0.63 & 0.2 & 5.4 & 3.7 & 126 & 52 & 4.0 \\
\hline India & 78 & 2.30 & 36.3 & 7.7 & 4.6 & 2 & 5 & 9.9 \\
\hline Cyprus & 86 & 0.03 & 0.0 & 5.0 & 5.3 & 46 & N.A. & 3.3 \\
\hline Mauritius & 87 & 0.01 & 0.0 & 5.8 & 4.7 & 14 & 26 & 8.8 \\
\hline Sri Lanka & 105 & 0.08 & 0.7 & 9.1 & 4.4 & 3 & N.A. & 9.1 \\
\hline Puerto Rico (USA) & 126 & 0.20 & 0.1 & 4.3 & 4.9 & 47 & N.A. & 12.0 \\
\hline Denmark & 144 & 0.73 & 0.3 & 5.9 & 2.6 & 124 & 68 & 4.5 \\
\hline New Zealand & 164 & 0.30 & 0.2 & 7.1 & 2.6 & 59 & 23 & 5.2 \\
\hline UK & 215 & 5.59 & 3.1 & 6.8 & 2.4 & 72 & 26 & 5.2 \\
\hline USA & 229 & 39.34 & 12.7 & 4.0 & 3.3 & 100 & 13 & 5.8 \\
\hline France & 242 & 6.59 & 2.7 & 5.3 & 3.2 & 97 & 6 & 9.0 \\
\hline Finland & 245 & 0.56 & 0.3 & 6.4 & 3.3 & 101 & 60 & 9.1 \\
\hline Peru & 247 & 0.22 & 0.7 & 280.9 & 3.1 & 7 & 8 & 8.9 \\
\hline Australia & 248 & 1.84 & 0.8 & 5.7 & 3.7 & 77 & 29 & 6.3 \\
\hline Trinidad \&Tobago & 264 & 0.05 & 0.0 & 7.1 & 3.8 & 17 & N.A. & 10.4 \\
\hline Spain & 272 & 2.05 & 1.7 & 8.6 & 4.1 & 57 & 10 & 11.4 \\
\hline Ireland & 281 & 0.24 & 0.1 & 7.4 & 5.0 & 96 & 36 & 4.4 \\
\hline Israel & 356 & 0.30 & 0.2 & 42.5 & 5.6 & 52 & 23 & 10.3 \\
\hline Canada & 402 & 3.45 & 1.4 & 4.5 & 3.7 & 74 & 37 & 7.6 \\
\hline Italy & 492 & 4.81 & 2.7 & 8.3 & 3.2 & 67 & 31 & 9.1 \\
\hline Guyana & 766 & 0.01 & 0.0 & 16.9 & 1.7 & 3 & 25 & 9.1 \\
\hline Iceland & 853 & 0.03 & 0.0 & 20.5 & 4.0 & 96 & 67 & 3.3 \\
\hline Nigeria & 1115 & 0.35 & 3.7 & 17.3 & 3.4 & 1 & 17 & 3.7 \\
\hline
\end{tabular}

Notes: (i) Days not worked per 1000 in the labour force. (ii) US\$ denominated Nominal GDP. (iv) Inflation measured via GDP deflator. (v) US\$ per capita GDP in 1995 prices (as at 2002).

Sources: For Column (i) International Labour Office (ILO), Yearbook of Labour Statistics plus ILO website: (http://laborsta.ilo.org/); Organization for Economic Cooperation and Development (OECD), Main Economic Indicators; Mitchell (2003a,b,c); Central Bank of Nigeria, Annual Report and Statement of Account. Certain refinements and updates were communicated directly to the authors via direct correspondence with respective national statistical collection agencies. Note: USA data are grossed up as described in the paper and Nigerian data after 1998 are based on the Authors' estimates as described in the paper. Labour force denominator from World Bank World Tables. For columns (ii) to (vi) World Bank World Tables. For Column (vii) Ebbinghaus and Visser (2000); Labour Market Trends, 'Trade Union Membership' (http://www.ilr.cornell.edu/library/downloads/FAQ/UNIONSTATS2002.pdf); ILO, World Labour Report 1997-98: Industrial Relations, Democracy and Social Stability, (http://www.ilo.org/public/english/dialogue/ifpdial/publ/wlr97/annex/tab11.htm). For column (viii) OECD, Economic Outlook; Asia Development Bank, Key Indicators; CIA, The World Factbook; The (Australian) Department of Foreign Affairs and Trade (DFAT): Country, economy and regional information website: http://www.dfat.gov.au/geo/; Central Bank of Nigeria, Annual Report and Statement of Account. Bangladesh and South African estimates include underemployment, the Nigeria estimate excludes underemployment. 
Table 5: Selected 'Global' Indexes

\begin{tabular}{|c|c|c|c|c|}
\hline & $\begin{array}{c}\text { 'Global' Stoppage } \\
\text { Rate \# } 1 \\
\text { (GDP Weighted) }\end{array}$ & $\begin{array}{l}\text { 'Global' Stoppage } \\
\text { Rate \# } 2 \\
\text { (GDP Weighted \& } \\
\text { Adjusted for } 1968 \\
\text { France) }\end{array}$ & $\begin{array}{l}\text { Non-USA 'Global' } \\
\text { Stoppage Rate \# } 3 \\
\text { (GDP Weighted) }\end{array}$ & $\begin{array}{l}\text { Non-USA 'Global' } \\
\text { Stoppage Rate \# } 4 \\
\text { (GDP Weighted \& } \\
\text { Adjusted for } 1968 \\
\text { France) }\end{array}$ \\
\hline 1960 & 173 & 173 & 84 & 84 \\
\hline 1961 & 176 & 176 & 136 & 136 \\
\hline 1962 & 213 & 213 & 184 & 184 \\
\hline 1963 & 173 & 173 & 143 & 143 \\
\hline 1964 & 198 & 198 & 121 & 121 \\
\hline 1965 & 188 & 188 & 100 & 100 \\
\hline 1966 & 231 & 231 & 161 & 161 \\
\hline 1967 & 306 & 306 & 131 & 131 \\
\hline 1968 & 823 & 343 & 1044 & 131 \\
\hline 1969 & 391 & 391 & 297 & 297 \\
\hline 1970 & 472 & 472 & 238 & 238 \\
\hline 1971 & 372 & 372 & 248 & 248 \\
\hline 1972 & 285 & 285 & 278 & 278 \\
\hline 1973 & 266 & 266 & 247 & 247 \\
\hline 1974 & 368 & 368 & 290 & 290 \\
\hline 1975 & 286 & 286 & 267 & 267 \\
\hline 1976 & 313 & 313 & 274 & 274 \\
\hline 1977 & 253 & 253 & 196 & 196 \\
\hline 1978 & 244 & 244 & 187 & 187 \\
\hline 1979 & 328 & 328 & 331 & 331 \\
\hline 1980 & 250 & 250 & 224 & 224 \\
\hline 1981 & 179 & 179 & 154 & 154 \\
\hline 1982 & 150 & 150 & 167 & 167 \\
\hline 1983 & 153 & 153 & 126 & 126 \\
\hline 1984 & 163 & 163 & 204 & 204 \\
\hline 1985 & 89 & 89 & 89 & 89 \\
\hline 1986 & 112 & 112 & 98 & 98 \\
\hline 1987 & 77 & 77 & 80 & 80 \\
\hline 1988 & 87 & 87 & 96 & 96 \\
\hline 1989 & 111 & 111 & 76 & 76 \\
\hline 1990 & 83 & 83 & 81 & 81 \\
\hline 1991 & 57 & 57 & 52 & 52 \\
\hline 1992 & 57 & 57 & 55 & 55 \\
\hline 1993 & 42 & 42 & 36 & 36 \\
\hline 1994 & 54 & 54 & 49 & 49 \\
\hline 1995 & 46 & 46 & 37 & 37 \\
\hline 1996 & 47 & 47 & 40 & 40 \\
\hline 1997 & 45 & 45 & 38 & 38 \\
\hline 1998 & 52 & 52 & 45 & 45 \\
\hline 1999 & 44 & 44 & 46 & 46 \\
\hline 2000 & 100 & 100 & 51 & 51 \\
\hline 2001 & 39 & 39 & 44 & 44 \\
\hline 2002 & 52 & 52 & 70 & 70 \\
\hline
\end{tabular}

Sources: refer to Text and Table 4 
Table 6: Correlation Coefficients for Global Indexes and Constituent Countries (classified by geographic regions)

\begin{tabular}{|c|c|c|c|c|}
\hline & $\begin{array}{l}\text { 'Global' } \\
\text { Stoppage } \\
\text { Rate \# } 1\end{array}$ & $\begin{array}{c}\text { 'Global' } \\
\text { Stoppage } \\
\text { Rate \# } 2\end{array}$ & \begin{tabular}{|c|} 
Non-USA \\
'Global' \\
Stoppage \\
Rate \# 3 \\
\end{tabular} & $\begin{array}{c}\text { Non-USA } \\
\text { 'Global' } \\
\text { Stoppage } \\
\text { Rate \# } 4 \\
\end{array}$ \\
\hline \multicolumn{5}{|l|}{ EUROPE: } \\
\hline Austria & 0.05 & 0.09 & 0.01 & 0.10 \\
\hline Denmark & -0.06 & -0.04 & -0.03 & 0.03 \\
\hline Finland & 0.18 & 0.26 & 0.14 & 0.34 \\
\hline France & 0.69 & 0.26 & 0.87 & 0.03 \\
\hline Germany & 0.13 & 0.21 & 0.09 & 0.28 \\
\hline Iceland & 0.42 & 0.38 & 0.37 & 0.27 \\
\hline Ireland & 0.58 & 0.71 & 0.42 & 0.70 \\
\hline Italy & 0.63 & 0.82 & 0.47 & 0.92 \\
\hline Netherlands & 0.04 & 0.11 & -0.01 & 0.11 \\
\hline Norway & -0.18 & -0.18 & -0.14 & -0.13 \\
\hline Spain & 0.02 & 0.11 & 0.05 & 0.31 \\
\hline Sweden & 0.04 & 0.09 & 0.03 & 0.14 \\
\hline Switzerland & -0.05 & -0.04 & -0.05 & -0.02 \\
\hline UK & 0.44 & 0.58 & 0.39 & 0.75 \\
\hline Average & 0.21 & 0.24 & 0.19 & 0.27 \\
\hline \multicolumn{5}{|l|}{ THE AMERICAS: } \\
\hline Canada & 0.64 & 0.76 & 0.53 & 0.81 \\
\hline Guyana & 0.36 & 0.37 & 0.29 & 0.31 \\
\hline Peru & 0.24 & 0.38 & 0.16 & 0.49 \\
\hline Puerto Rico & 0.41 & 0.56 & 0.27 & 0.59 \\
\hline Trinidad \&Tobago & 0.24 & 0.36 & 0.17 & 0.47 \\
\hline USA & 0.90 & 0.96 & 0.65 & 0.71 \\
\hline Average & 0.46 & 0.56 & 0.35 & 0.56 \\
\hline \multicolumn{5}{|l|}{ ASIA \& OCEANIA: } \\
\hline Australia & 0.55 & 0.72 & 0.41 & 0.82 \\
\hline Bangladesh & 0.27 & 0.27 & 0.32 & 0.32 \\
\hline Cyprus & 0.10 & 0.05 & 0.17 & 0.12 \\
\hline India & 0.14 & 0.19 & 0.18 & 0.36 \\
\hline Israel & -0.38 & -0.39 & -0.27 & -0.25 \\
\hline Japan & 0.53 & 0.65 & 0.35 & 0.58 \\
\hline Korea (South) & -0.38 & -0.44 & -0.29 & -0.41 \\
\hline Malaysia & 0.26 & 0.20 & 0.25 & 0.10 \\
\hline New Zealand & 0.15 & 0.22 & 0.14 & 0.33 \\
\hline Pakistan & 0.40 & 0.55 & 0.16 & 0.40 \\
\hline Philippines & 0.11 & 0.15 & 0.06 & 0.13 \\
\hline Singapore & 0.01 & 0.04 & -0.03 & 0.00 \\
\hline Sri Lanka & 0.31 & 0.32 & 0.20 & 0.18 \\
\hline Thailand & 0.08 & 0.16 & 0.09 & 0.32 \\
\hline Average & 0.15 & 0.19 & 0.13 & 0.22 \\
\hline \multicolumn{5}{|l|}{ AFRICA: } \\
\hline South Africa & -0.47 & -0.54 & -0.34 & -0.47 \\
\hline Mauritius & 0.31 & 0.42 & 0.29 & 0.56 \\
\hline Morocco & 0.23 & 0.34 & 0.18 & 0.44 \\
\hline Nigeria & -0.45 & -0.53 & -0.35 & -0.53 \\
\hline Average & -0.09 & -0.08 & -0.06 & 0.00 \\
\hline Overrall Average & 0.20 & 0.24 & 0.17 & 0.27 \\
\hline
\end{tabular}


Table 7: Correlation Coefficients for Global Indexes and Non-Constituent Countries (classified by geographic regions)

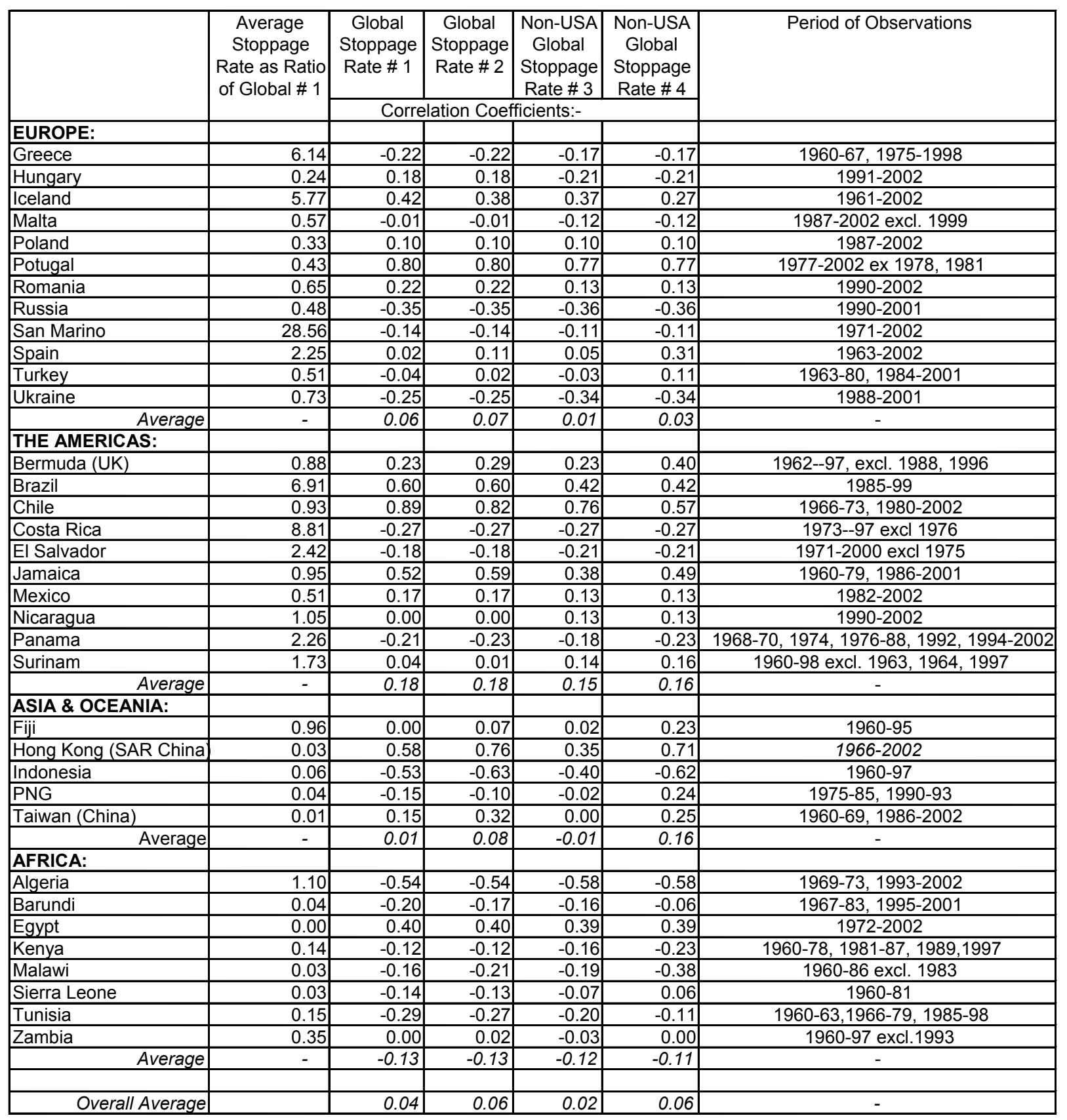

Sources: Refer to Table 4 plus Directorate-General of Budget, Accounting and Statistics, Executive Yuan, Statistical Yearbook of the Republic of China and Monthly Bulletin of Statistics and Census and Statistics Department, Hong Kong in Figures. 
Table 8: East Asian Relative Stoppage Rates*

\section{Country/Territory}

Average Stoppage Rate as a Percent of Global \#1

\begin{tabular}{ll}
\hline Taiwan (China) & 0.93 \\
Hong Kong (China) & 2.87 \\
Thailand & 3.87 \\
Indonesia & 6.19 \\
Malaysia & 10.23 \\
Japan & 16.70 \\
Singapore & 28.25 \\
Philippines & 36.76 \\
South Korea & 73.01 \\
* These are the mean percentage values of the yearly ratio of (i) a particular country's stoppage rate to (ii) the Global stoppage rate index \# 1. The \\
calculations are for matched values when there are missing observations.
\end{tabular}
calculations are for matched values when there are missing observations.

Table 9: Conventional ADF Unit Root Tests

\begin{tabular}{lcc}
\hline Variable (in logs) & Levels & \multicolumn{2}{c}{ Differences } \\
\hline USA & -2.38 & $-3.64^{\mathrm{b}}$ \\
NonUSA & -2.18 & $-5.03^{\mathrm{b}}$ \\
NonUSAEX & -1.55 & $-4.21^{\mathrm{b}}$ \\
NAM & -2.40 & $-3.46^{\mathrm{b}}$ \\
NoNAM & -2.25 & $-5.30^{\mathrm{b}}$ \\
NoNAMEX & -1.57 & $-4.40^{\mathrm{b}}$
\end{tabular}

bAll series are first difference stationary at the $5 \%$ level. Lag length is determined by the largest lag based on each of: LR, FPE,AIC,SC and HQ tests. 
Table 10: Zivot and Andrews Unit Root Tests

\begin{tabular}{lccc}
\hline & $\begin{array}{c}\text { ZA Model Type } \\
\text { (approx. breakdate) }\end{array}$ & B & C \\
Variable (in Logs) & A & & $-6.69^{\mathrm{a}}$ \\
\hline & $-7.79^{\mathrm{a}}$ & $-4.76^{\mathrm{b}}$ & $(1985)$ \\
USA & $(1985)$ & $(1969)$ & $-5.64^{\mathrm{a}}$ \\
NonUSA & $-5.73^{\mathrm{a}}$ & $-7.66^{\mathrm{a}}$ & $(1968)$ \\
NonUSAEX & $(1968)$ & $(1991)$ & -4.16 \\
& $-4.78^{\mathrm{c}}$ & -3.99 & $-6.65^{\mathrm{a}}$ \\
NAM & $(1991)$ & & $(1985)$ \\
NoNAM & $-6.19 \mathrm{a}$ & $-4.57^{\mathrm{c}}$ & $-6.30^{\mathrm{a}}$ \\
NoNAMEX & $(1985)$ & $(1969)$ & $(1968)$ \\
Significance: $\mathrm{a}=1 \%, \mathrm{~b}=5 \%, \mathrm{c}=10 \%$. Lag length determined by ZA procedure & -4.07 & $-4.86^{\mathrm{c}}$ \\
\end{tabular}

Table 11: Johansen Rank Tests*.

\begin{tabular}{ccccccccc}
\hline & \multicolumn{1}{c}{ USA and NonUSA } & \multicolumn{2}{c}{$\begin{array}{c}\text { USA and } \\
\text { NonUSAEX }\end{array}$} & \multicolumn{2}{c}{ NAM and NoNAM NAM and } \\
& \multicolumn{1}{c}{ NonAMEX } \\
\cline { 2 - 9 }$H_{0}:$ & $\lambda_{\text {Trace }}$ & $\lambda_{\text {Max }}$ & $\lambda_{\text {Trace }}$ & $\lambda_{\text {Max }}$ & $\lambda_{\text {Trace }}$ & $\lambda_{\text {Max }}$ & $\lambda_{\text {Trace }}$ & $\lambda_{\text {Max }}$ \\
\hline$r=0$ & $26.99^{\mathrm{b}}$ & 14.52 & $34.15^{\mathrm{b}}$ & $22.13^{\mathrm{b}}$ & $26.69^{\mathrm{b}}$ & $21.40^{\mathrm{b}} .8 .228 .02^{\mathrm{b}}$ & $17.85^{\mathrm{c}}$ \\
$r \leq 1$ & 12.47 & 12.47 & 12.02 & 12.02 & 8.29 & 9 & 10.17 & 10.17 \\
\hline
\end{tabular}

*The results presented are the Johansen trace and maximum Eigenvalue statistics. Results tabulated assume a trend component and critical values are taken from Mackinnon-Haug-Michelis (1999). A sequential estimation procedure was used to determine lag order. a indicates reject null at $1 \%$, $b$ at $5 \%$ and ${ }^{c}$ at $10 \%$ 
Table 12: Inoue Rank Tests.

\begin{tabular}{|c|c|c|c|c|c|c|}
\hline \multicolumn{7}{|c|}{ USA and NonUSA } \\
\hline \multirow[t]{2}{*}{$H_{0}:$} & \multicolumn{2}{|c|}{ Model A } & \multicolumn{2}{|c|}{ Model B } & \multicolumn{2}{|c|}{ Model C } \\
\hline & $\lambda_{\text {Trace }}$ & $\lambda_{\operatorname{Max}}$ & $\lambda_{\text {Trace }}$ & $\lambda_{\operatorname{Max}}$ & $\lambda_{\text {Trace }}$ & $\lambda_{\operatorname{Max}}$ \\
\hline$r=0$ & $\begin{array}{c}34.10^{\mathrm{b}} \\
(1981)\end{array}$ & $27.58^{b}$ & $\begin{array}{c}52.52^{\mathrm{a}} \\
(1967)\end{array}$ & $36.42^{\mathrm{a}}$ & $\begin{array}{c}34.18^{\mathrm{a}} \\
(1980)\end{array}$ & $27.51^{\mathrm{b}}$ \\
\hline$r \leq 1$ & 7.27 & 7.27 & 16.08 & 16.08 & 8.33 & 8.33 \\
\hline \multicolumn{7}{|c|}{ USA and NonUSAEX } \\
\hline \multirow{2}{*}{$H_{0}:$} & \multicolumn{2}{|c|}{ Model A } & \multicolumn{2}{|c|}{ Model B } & \multicolumn{2}{|c|}{ Model C } \\
\hline & $\lambda_{\text {Trace }}$ & $\lambda_{\operatorname{Max}}$ & $\lambda_{\text {Trace }}$ & $\lambda_{\operatorname{Max}}$ & $\lambda_{\text {Trace }}$ & $\lambda_{\operatorname{Max}}$ \\
\hline$r=0$ & 25.22 & $\begin{array}{l}24.81^{b} \\
(1981)\end{array}$ & $\begin{array}{c}38.17^{\mathrm{c}} \\
(1967)\end{array}$ & $28.43^{\mathrm{c}}$ & $\begin{array}{c}26.25^{\mathrm{c}} \\
(1981)\end{array}$ & $23.41^{\mathrm{c}}$ \\
\hline$r \leq$ & 7.23 & 7.23 & 11.67 & 11.67 & 7.98 & 7.98 \\
\hline \multicolumn{7}{|c|}{ NAM and NoNAM } \\
\hline \multirow[t]{2}{*}{$H_{0}:$} & \multicolumn{2}{|c|}{ Model A } & \multicolumn{2}{|c|}{ Model B } & \multicolumn{2}{|c|}{ Model C } \\
\hline & $\lambda_{\text {Trace }}$ & $\lambda_{\operatorname{Max}}$ & $\lambda_{\text {Trace }}$ & $\lambda_{\operatorname{Max}}$ & $\lambda_{\text {Trace }}$ & $\lambda_{\operatorname{Max}}$ \\
\hline$r=0$ & $\begin{array}{c}32.46^{\mathrm{b}} \\
(1978)\end{array}$ & $27.73^{b}$ & $\begin{array}{c}57.08^{\mathrm{a}} \\
(1967)\end{array}$ & $42.10^{\mathrm{a}}$ & $\begin{array}{l}34.50^{\mathrm{a}} \\
(1981)\end{array}$ & $28.17^{\mathrm{a}}$ \\
\hline$r \leq 1$ & 7.29 & 7.29 & 15.58 & 15.58 & 8.06 & 8.06 \\
\hline & & & $\mathrm{M}$ and NoN & & & \\
\hline$H_{0}:$ & & lel A & & el B & Mode & el C \\
\hline & $\lambda_{\text {Trace }}$ & $\lambda_{\operatorname{Max}}$ & $\lambda_{\text {Trace }}$ & $\lambda_{\operatorname{Max}}$ & $\lambda_{\text {Trace }}$ & $\lambda_{\operatorname{Max}}$ \\
\hline$r=0$ & $\begin{array}{c}24.34 \\
(1967)\end{array}$ & $24.12^{\mathrm{c}}$ & $\begin{array}{c}40.18^{\mathrm{c}} \\
(1968)\end{array}$ & 28.39 & 24.35 & 19.52 \\
\hline$r \leq 1$ & 7.02 & 7.02 & 12.10 & 12.10 & 7.61 & 7.61 \\
\hline
\end{tabular}

Critical values for the trace and maximum Eigenvalue statistics are taken from Inoue (1999). a indicates reject null at $1 \%,{ }^{b}$ at $5 \%$ and $\mathrm{c}$ at $10 \%$ 
Figures 
Figure 1: USA Time Lost due to Work Stoppages

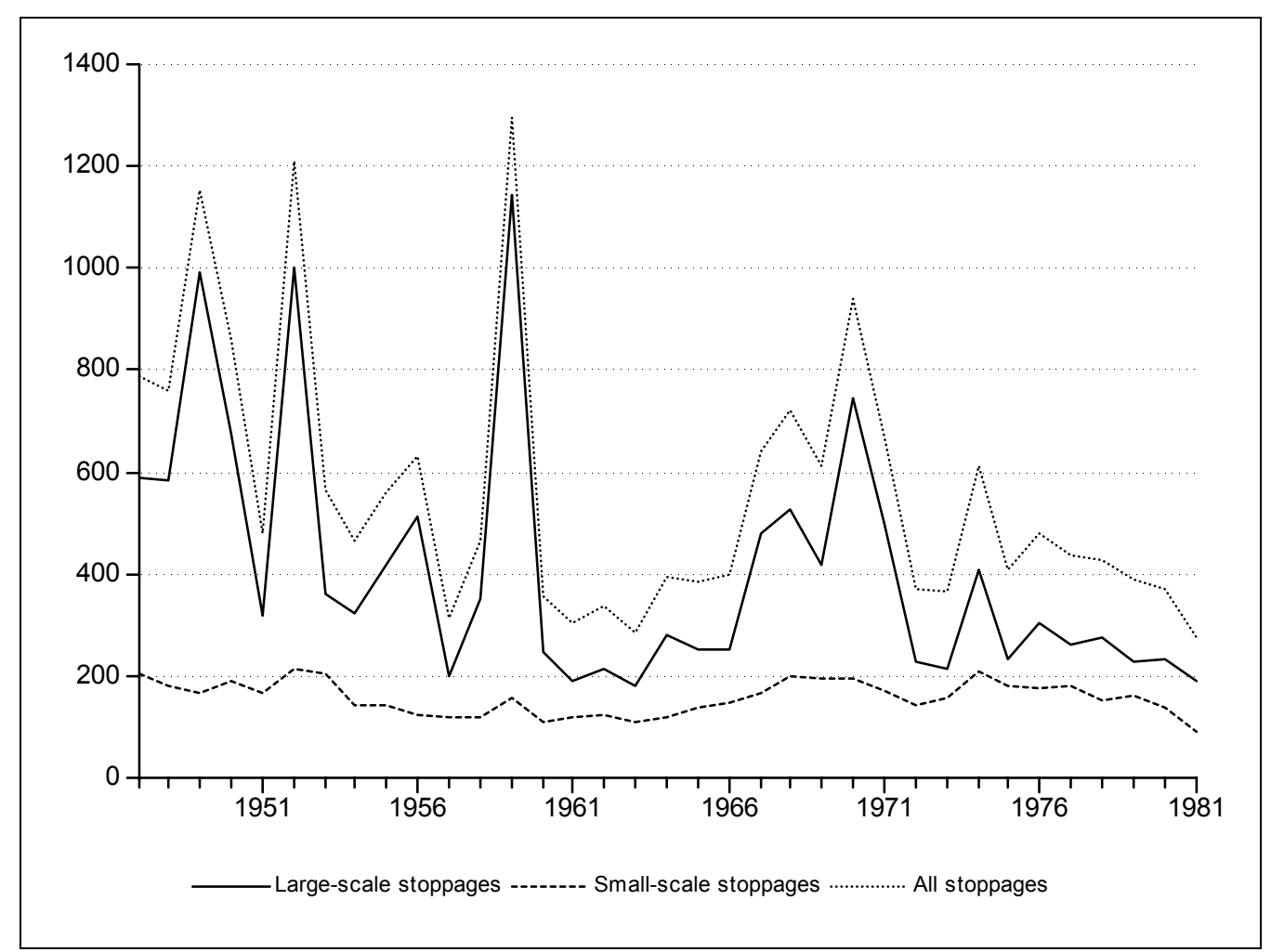

Figure 2: Trends in Small-Scale and Large-Scale Work Stoppages

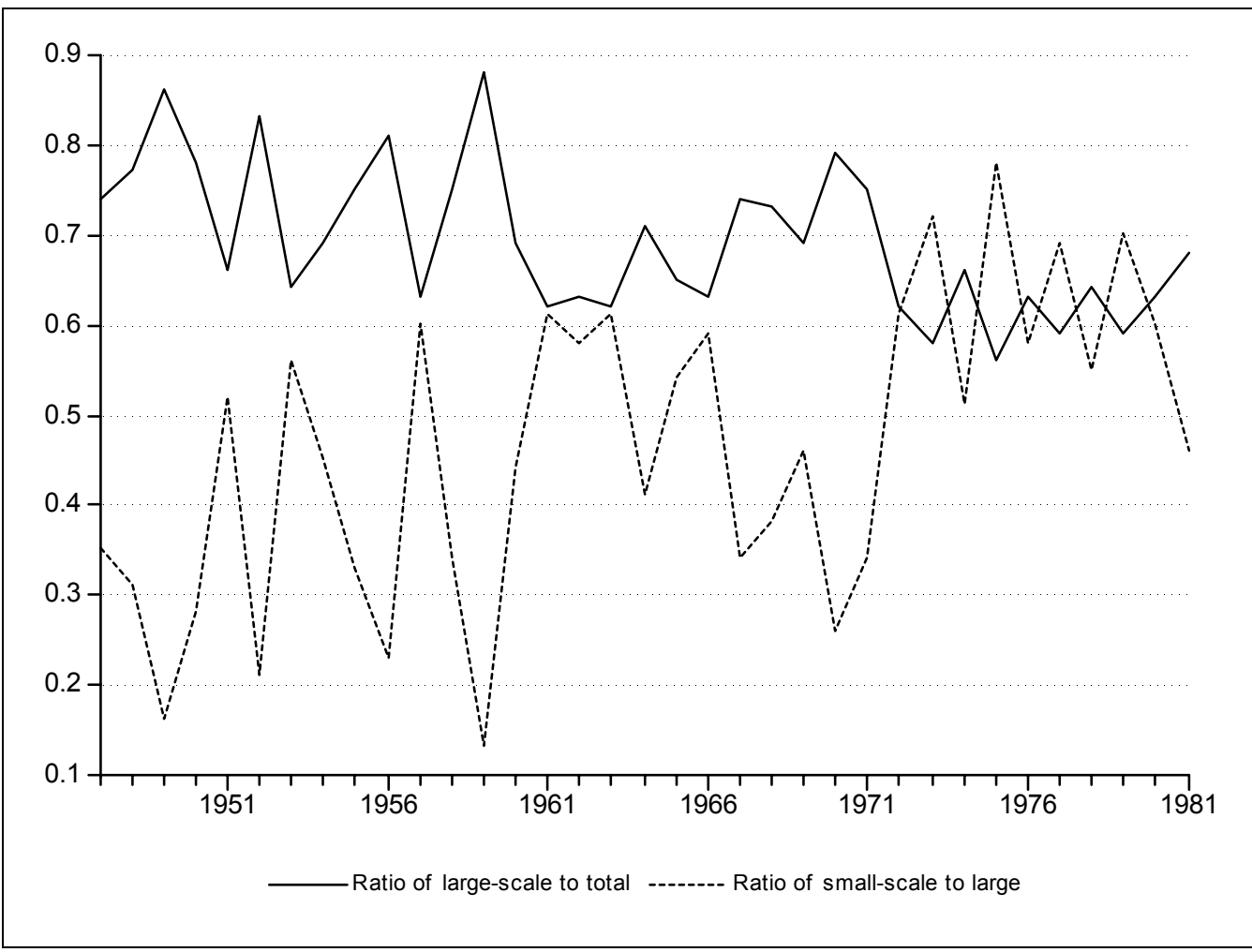


Figure 3: Measurement Differences in Days Lost: Australia 1913-2003

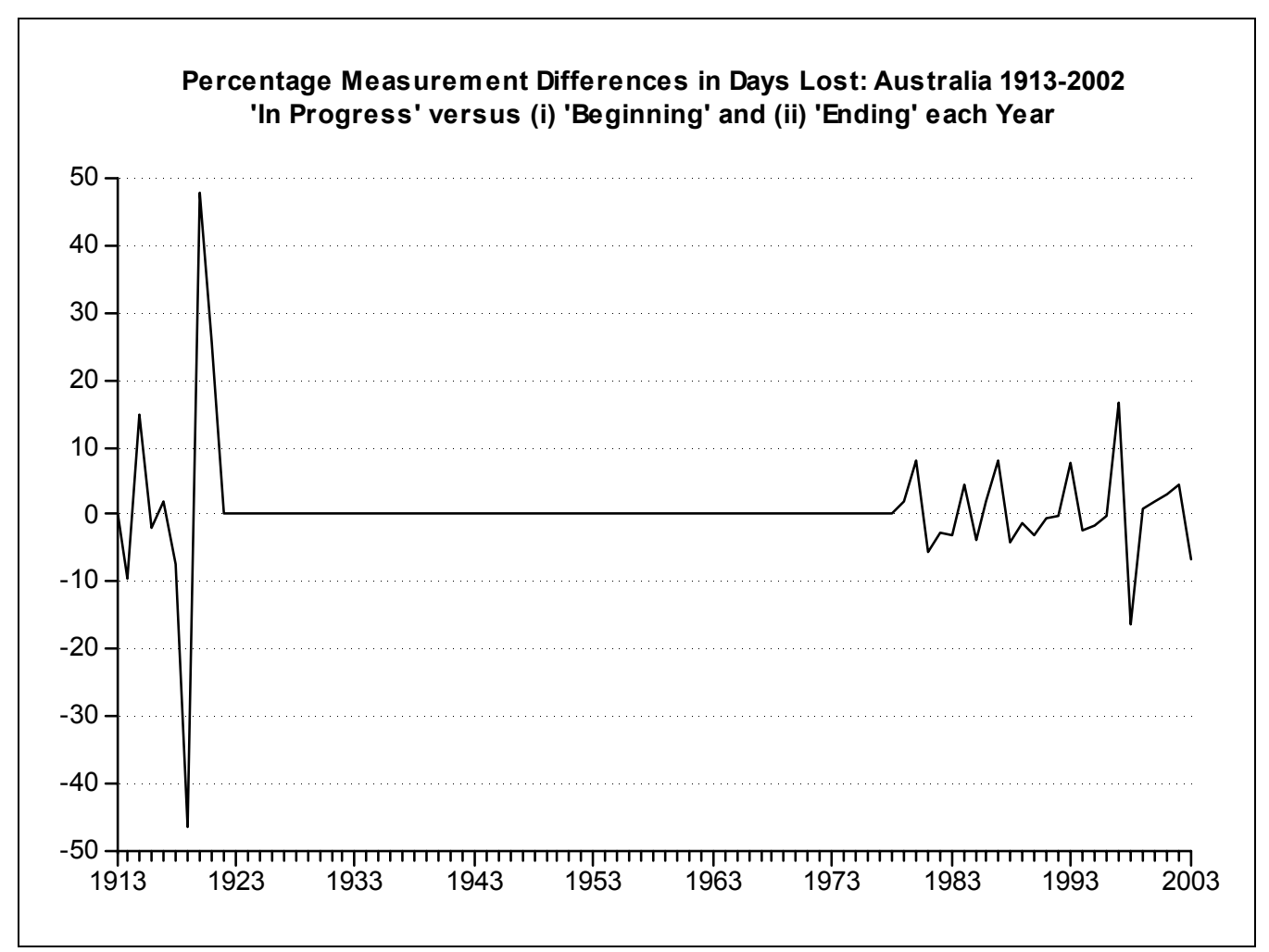


Figure 4: Preliminary 'Global' Indexes

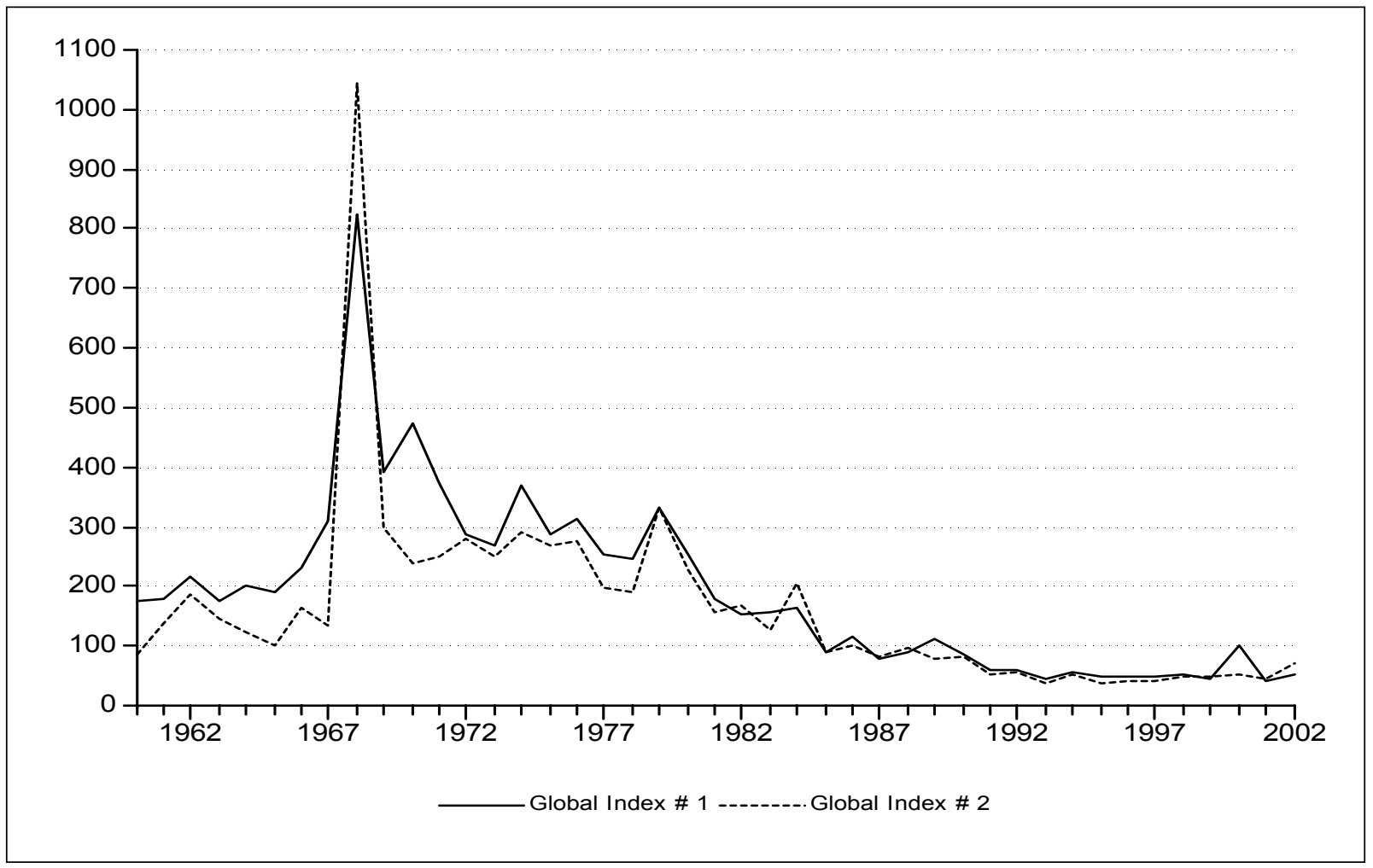

Figure 5: Global Index Compared with Mexico, Russia and Taiwan (China)

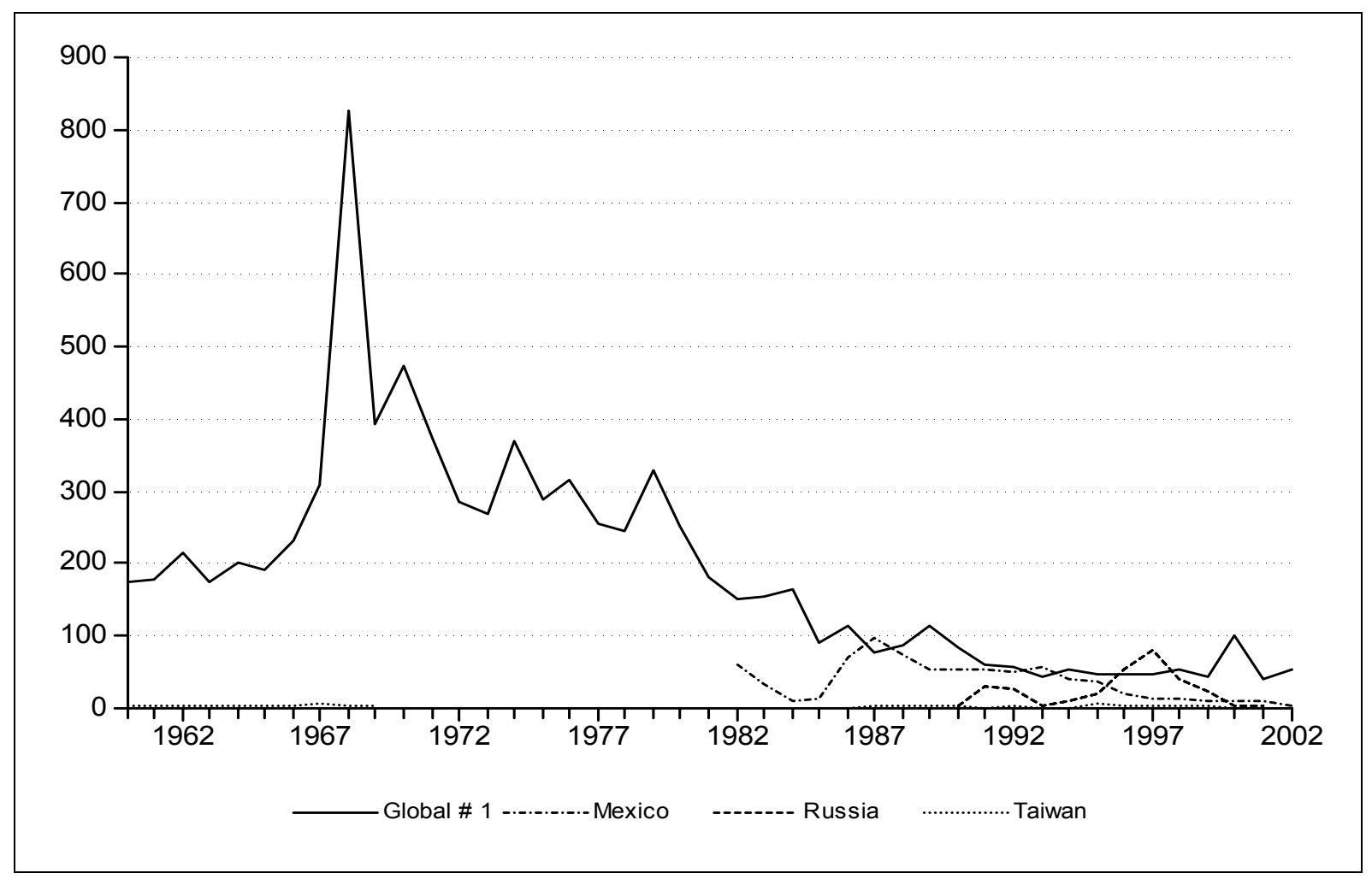


Figure 6: Global Index Compared with Turkey, Indonesia and Hong Kong (China)

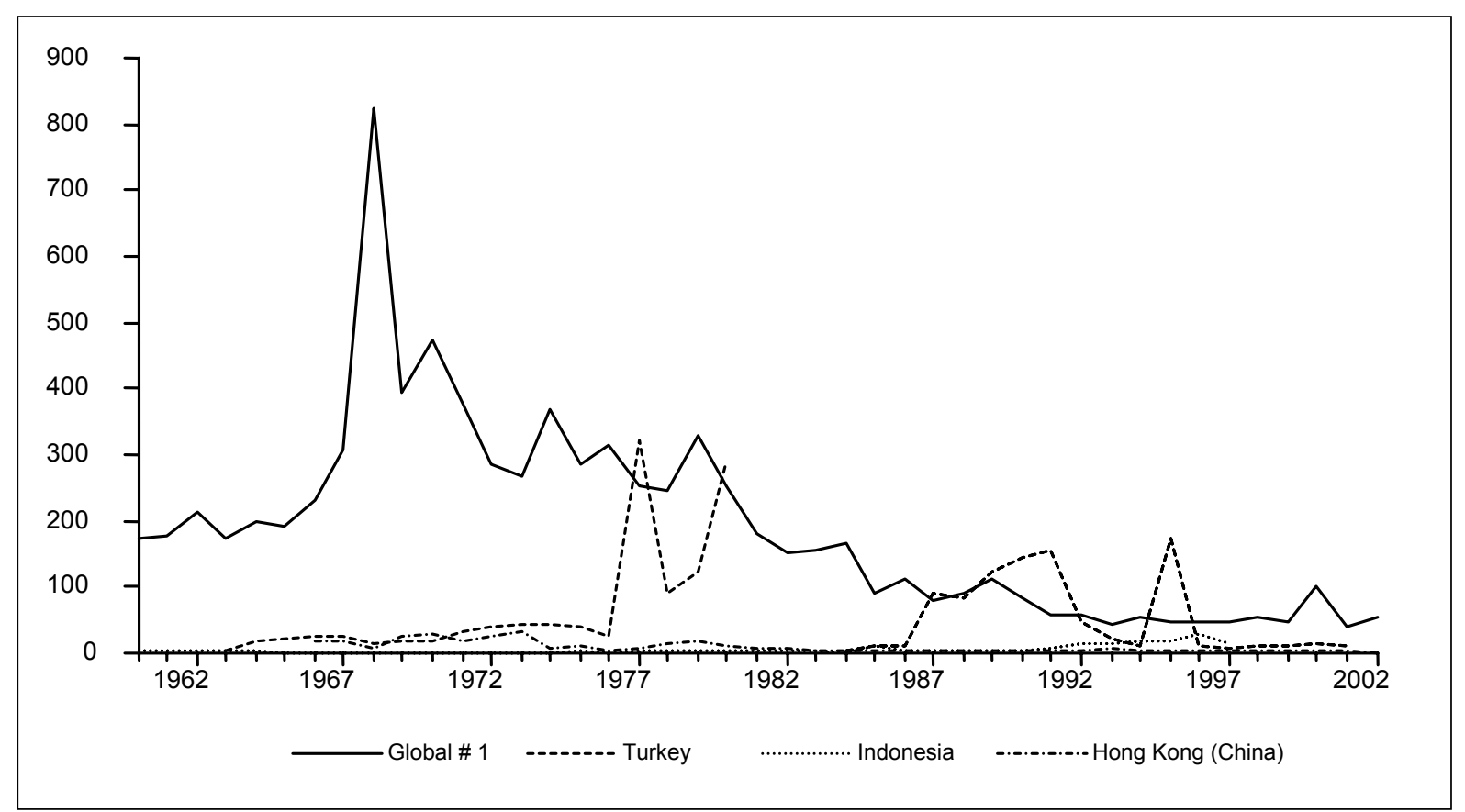




\section{Appendix A: More on Zivot and Andrews}

Zivot and Andrews (1992) developed an objective procedure that sequentially tested for unit roots in the presence of potential, but unknown, breaks in data series. The Zivot and Andrews (ZA) terminology followed that of Perron (1989) and allowed tests for three possible situations: clear break in trend (crash); break in trend slope; and both conditions. The models were simply called A, $\mathrm{B}$ and $\mathrm{C}$ and the augmented regressions for testing were given as:

\section{Model A}

$$
y_{t}=\hat{\mu}^{A}+\hat{\theta}^{A} D U_{t}(\hat{\lambda})+\hat{\beta}^{A} t+\hat{\alpha}^{A} y_{t-1}+\sum_{j=1}^{k} \hat{c}_{j}^{A} \Delta y_{(t-j)}+\hat{e}_{t}
$$

Model B

$$
y_{t}=\hat{\mu}^{B}+\hat{\beta}^{B} t+\hat{\gamma}^{B} D T_{t}^{*}(\hat{\lambda})+\hat{\alpha}^{B} y_{t-1}+\sum_{j=1}^{k} \hat{c}_{j}^{B} \Delta y_{(t-j)}+\hat{e}_{t}
$$

Model C

$$
y_{t}=\hat{\mu}^{C}+\hat{\theta}^{C} D U_{t}(\hat{\lambda})+\hat{\beta}^{C} t+\hat{\gamma}^{C} D T_{t}^{*}(\hat{\lambda})+\hat{\alpha}^{C} y_{t-1}+\sum_{j=1}^{k} \hat{c}_{j}^{C} \Delta y_{(t-j)}+\hat{e}_{t}
$$

where: $\lambda$ is the break fraction determined as a ratio of the given period number to the total number of periods; $D U_{\mathrm{t}}(\lambda)=1$ if $t>T \lambda$, and 0 otherwise; $D T^{*}{ }_{\mathrm{t}}(\lambda)=t-T \lambda$ if $t>T \lambda$ and 0 otherwise. In the modelling process the breakpoint $D U_{\mathrm{t}}$ is chosen as the minimum $t$-value on $\alpha^{\mathrm{i}} \quad(\mathrm{i}=\mathrm{A}, \mathrm{B}, \mathrm{C})$ for sequential tests of the breakpoint occurring at time $1<\mathrm{T}_{\mathrm{B}}<\mathrm{T}$ in the above regressions. In the ZA methodology the null hypothesis is that the series $\left\{y_{\mathrm{t}}\right\}$ is integrated without an exogenous structural break against the alternative that the series $\left\{y_{\mathrm{t}}\right\}$ can be represented by a trend-stationary process with a once only breakpoint occurring at some unknown time. The smallest $t$-values are compared with a set of critical values developed by Zivot and Andrews. In addition to testing for a unit root in the presence of a potential breakpoint, the ZA procedure provides an approximation for the break date. In the ZA procedure the approximation may miss the 'true' breakdate by a couple of periods due to the estimation process. If the data frequency is, say, weekly or monthly this is inconsequential. Unfortunately if the frequency is annual the approximate dating is poor. Since the ZA procedure is a unit root testing process rather than a break dating process no confidence intervals are developed for the estimated break dates. 


\section{Appendix B: More on Inoue}

Inoue (1999), among others, showed that if one or more of the series contain a break in trend this may yield misleading results as to the rank of the cointegration system (and whether there is cointegration at all). As was the case with Zivot and Andrews (1992), the procedure developed by Inoue (1999) determines any break endogenously for a test of cointegrating rank within the presence of a possible (but unknown) trend-break. While other procedures are available (cf. Gregory and Hansen (1996)), a significant advantage for present purposes is that Inoue is a Johansen (1991) type test and therefore does not require prior specification of the structure of a cointegrating equation. The Inoue (1999) results therefore allow direct comparison with the Johansen (1991) outcome.

The Inoue (1999) methodology follows closely that of the Johansen type tests and, in a somewhat similar approach to the individual series tests of Zivot and Andrews (1992), three models are examined (A, B and C) that allow for possible mean and trend breaks. As Inoue (1999) outlines, the models can be written as $n$-dimensional vector autoregressions (VAR) such that:

$$
\begin{aligned}
& Y_{t}^{i}\left(\xi_{0}\right)=\sum_{j=1}^{p} \Phi_{j} Y_{t-j}^{i}\left(\xi_{0}\right)+u_{t}, i=A, B, \\
& Y_{t}^{A}(\xi)=X_{t}-\mu-\tilde{\mu} D U_{t}(\xi), \\
& Y_{t}^{B}(\xi)=X_{t}-\mu-\tilde{\mu} D U_{t}(\xi)-\delta t-\widetilde{\delta} D T_{t}(\xi), \\
& Y_{t}^{C}=c+\widetilde{\mu} D U_{t}\left(\xi_{0}\right)+\sum_{j=1}^{p} \Phi_{j} Y_{t-j}^{C}+u_{t}, Y_{t}^{C}=X_{t},
\end{aligned}
$$

where $u_{1} \sim N I D\left(0_{n x 1}, \Omega\right), c, \mu, \widetilde{\mu}, \delta$ and $\widetilde{\delta}$ are n-dimensional vectors, $\left\{\phi_{j}\right\}_{j}^{p}={ }_{1}$ are $n \times n$ matrices, $D U_{t}(\xi)=I(t>[T \xi])$ and $D T_{t}(\xi)=(t-[T \xi]) I(t>[T \xi])$ where $I(\xi)$ denotes the indicator function and $[x]$ denotes the integer part of $x . \xi_{0} \in \Xi$ is the break fraction where $\Xi$ is a closed subset of $(0,1)$.

As in the Johansen (1991) procedure the above equations can also be written in an error-correction form, such that:

$$
\begin{aligned}
& \Delta Y_{t}^{i}\left(\xi_{0}\right)=\Pi Y_{t-1}^{i}\left(\xi_{0}\right)+\sum_{j=1}^{p-1} \Gamma_{j} \Delta Y_{t-j}^{i}\left(\xi_{0}\right)+u_{t} i=A, B, \\
& \Delta Y_{t}^{c}=c+\widetilde{\mu} D U_{t}\left(\xi_{0}\right)+\Pi Y_{t-1}^{c}+\sum_{j=1}^{p-1} \Gamma_{j} \Delta Y_{t-j}^{c}+u_{t}
\end{aligned}
$$

where $\left\{\Gamma_{j}\right\}_{j=1}^{p-1}$ and $\Pi$ are $n \times n$ matrices, $q$ and $r$ are integers such that $1 \leq q \leq n$ and $0 \leq r \leq q$ and $\alpha$ and $\beta$ are $n \times q$ matrices such that $\alpha \beta^{\prime}=\Pi$. From this Inoue (1999) develops trace and maximum eigenvalue statistics that are similar in taxonomy to Johansen (1991) such that the null hypothesis of

$$
H_{0}: \operatorname{rank}(\alpha)=\operatorname{rank}(\beta) \leq r, \tilde{\mu}=\delta=0_{n \times 1}
$$

can be tested against either the alternative:

$$
H_{1}: \operatorname{rank}(\alpha)=\operatorname{rank}(\beta)=r+1
$$


using the trace stastistic:

$$
\sup _{\xi \in \Xi}\left\{-T \sum_{j=r+1}^{T} \ln \left(1-\hat{\lambda}_{j}^{i}(\xi)\right)\right\} ;
$$

or, by applying the maximum eigenvalue statistic:

$\sup _{\xi \in \Xi}\left\{-T \ln \left(1-\hat{\lambda}_{r+1}^{i}(\xi)\right)\right\}$,

one can test against the alternative:

$$
H_{2}: \operatorname{rank}(\alpha)=\operatorname{rank}(\beta)>r .
$$

Inoue (1999) provides asymptotic critical values for these test statistics as well as evidence that these tests are more appropriate than the standard Johansen methodology where trend-breaks are present. 


\section{Policy Integration Department Working Papers}

No. 1 ILO activities on the social dimension of globalization: Synthesis report

No. 2 Measuring decent work with statistical indicators, Richard Anker, Igor Chernyshev, Philippe Egger, Farhad Mehran and Joseph Ritter

No. 3 Globalization and decent work: Options for Panama Philippe Egger

No. 4 Globalización y trabajo decente: Opciones para Panamá, Philippe Egger

No. 5 Indicators of social dialogue: Concepts and measurements, Lane Kenworthy and Bernhard Kittel

No. 6 Assessing the impact of the attacks of 11 September 2001 on women's employment in the United States, Gertrude Schaffner Goldberg and Helen Lachs Ginsburg

No. 7 Decent work and the informal economy in Central America, Juan Diego Trejos Solórzano and Miguel Del Cid

No. 8 Poverty initiatives in the ILO: A review of past and present approaches, Pat Holden and Dagmar Walter

No. 9 Whither the International Standard Classification of Occupations (ISCO-88)?, Debbie Budlender

No. 10 Improving occupational classifications as tools for describing labour markets: A summary of recent national experiences, Debbie Budlender

No. 11 Recent developments in China's labour economy, Thomas G. Rawski

No. 12 The Impact of economic liberalization on employment and wages in India, Sonia Bhalotra

No. 13 The impact of trade liberalization upon inequality in developing countries, Donald J. Robbins

No. 14 The impact of liberalization and globalization on income inequality in developing and transitional economies, Giovanni Andrea Cornia

No. 15 The impact of technology transfer on employment and income distribution in developing countries: A survey of theoretical models and empirical studies, Mariacristina Piva 


\section{Policy Integration Department Working Papers prepared for the World Commission on the \\ Social Dimension of Globalization}

No. 16 International finance: Meeting the needs of people in developing countries, José Guilherme Almeida dos Reis

No. 17 The gender dimensions of globalization of production, Stephanie Barrientos, Naila Kabeer and Naomi Hossain

No. 18 Social exclusion in the context of globalization, Jan Breman

No. 19 Gender and globalization: A macroeconomic perspective, Çağatay Nilüfer and Ertük Korkurt

No. 20 Globalization, social exclusion, and work: with special reference to informal employment and gender, Marilyn Carr and Martha Chen

No. 21 Resources for social development, Antony Clunies Ross

No. 22 Does the new international trade regime leave room for industrialization policies in the middle-income countries?, Alisa DiCaprio and Alice Amsden

No. 23 Social dimension of globalization in Latin America: Lessons from Bolivia and Chile, Alvaro García Hurtado

No. 24 The social dimension of globalization: a review of the literature, Bernhard Gunter and Rolph van der Hoeven

No. 25 The social dimension of global production systems, Susan Hayter

No. 26 Reforming global economic and social governance: a critical review of recent programmatic thinking, Jeremy Heimans

No. 27 Corporate social responsibility: an issues paper, Michael Hopkins

No. 28 Upgrading in global value chains, John Humphrey

No. 29 Implications of globalization and economic restructuring for skills development in Sub-Saharan Africa, Richard K. Johanson

No. 30 The outcome and impact of the main international commissions on development issues, Frédéric Lapeyre

No. 31 Globalization and structural adjustment as a development tool, Frédéric Lapeyre

No. 32 Globalization and perceptions of social inequality, Malte Luebker

No. 33 The changing structure of international trade linked to global production systems: what are the policy implications?, William Milberg

No. 34 Corporate social responsibility: an overview of principles and practice, Jill Murray

No. 35 Inclusive development strategy in an era of globalization, Ignacy Sachs

No. 36 Social consequences of the globalization of the media and communication sector: some strategic considerations, Seán Ó. Siochrú

No. 37 Globalization, history and international migration: a view from Latin America, Andrés Solimano

No. 38 Towards a different kind of globalization, or how the anti-globalists view the world, Gijsbert van Liemt 


\section{Policy Integration Department Working Papers}

No. 39 How do trade union rights affect trade competitiveness?

David Kucera and Ritash Sarna

No. 40 Statistics on the employment situation of people with disabilities: A compendium of national methodologies

ILO Bureau of Statistics in collaboration with the In Focus Programme on Skills, Knowledge and Employability

No. 41 Employment in the informal economy in the Republic of Moldova ILO Bureau of Statistics in collaboration with the Department for Statistics and Sociology of the Republic of Moldova

No. 42 Decent work in a least developed country: A critical assessment of the Ethiopia PRSP, Graeme J. Buckley

No. 43 Unemployment and Labour Market Institutions: The Failure of the Empirical Case for Deregulation,

Dean Baker, Andrew Glyn, David Howell and John Schmitt

No. 44 Women's access to occupations with authority, influence and decision-making power: Women as legislators, senior officials and managers around the world, Richard Anker.

No. 45 The world of work in the context of economic integration and trade liberalization, Daniel Martínez

No. 46 Poverty reduction in Pakistan: The strategic impact of macro and employment policies, Moazam Mahmood

No. 47 Trends in Work Stoppages: A Global Perspective, L. J. Perry and Patrick J. Wilson 